\title{
SWATH-MS based quantitative proteomics analysis reveals that curcumin alters the metabolic enzyme profile of CML cells by affecting the activity of miR-22/IPO7/HIF-1a axis
}

Francesca Monteleone ${ }^{1 \dagger}$, Simona Taverna ${ }^{2 \dagger}$, Riccardo Alessandro $^{1,2^{*}}$ and Simona Fontana ${ }^{1 *}$

\begin{abstract}
Background: Chronic myelogenous leukemia $(C M L)$ is a myeloproliferative disorder caused by expression of the chimeric BCR-ABL tyrosine kinase oncogene, resulting from the $t(9 ; 22)$ chromosomal translocation. Imatinib (gleevec, STI-571) is a selective inhibitor of BCR-ABL activity highly effective in the treatment of CML. However, even though almost all CML patients respond to treatment with imatinib or third generation inhibitors, these drugs are not curative and need to be taken indefinitely or until patients become resistant. Therefore, to get a definitive eradication of leukemic cells, it is necessary to find novel therapeutic combinations, for achieving greater efficacy and fewer side effects.

Curcumin is an Indian spice with several therapeutic properties: anti-oxidant, analgesic, anti-inflammatory, antiseptic and anti-cancer. In cancer disease, it acts by blocking cell transformation, proliferation, and invasion and by inducing cell apoptosis.
\end{abstract}

Methods: In the present study, the effect of a sub-toxic dose of curcumin on K562 cells was evaluated by using the technique of Sequential Window Activation of All Theoretical Mass Spectra (SWATH-MS). Bioinformatic analysis of proteomic data was performed to highlight the pathways mostly affected by the treatment. The involvement of Hypoxia inducible factor 1 a (HIF-1a) was assayed by evaluating its activation status and the modulation of importin 7 (IPO7) and miR-22 was assessed by quantitative PCR and western blot analysis. Finally, K562 cells transfected with miR-22 inhibitor were used to confirm the ability of curcumin to elicit miR-22 expression.

Results: Our findings revealed that the most relevant effect induced by curcumin was a consistent decrease of several proteins involved in glucose metabolism, most of which were HIF-1a targets, concomitant with the upregulation of functional and structural mitochondrial proteins. The mechanism by which curcumin affects metabolic enzyme profile was associated with the reduction of HIF-1a activity, due to the miR-22-mediated down-regulation of IPO7 expression. Finally, the ability of curcumin to enhance in vitro the efficiency of imatinib was reported.

Conclusions: In summary, our data indicates that the miR-22/IPO7/HIF-1a axis may be considered as a novel molecular target of curcumin adding new insights to better define therapeutic activity and anticancer properties of this natural compound. The MS proteomic data have been deposited to the ProteomeXchange with identifier <PXD007771>.

Keywords: Curcumin, CML cells, SWATH-MS, miR-22/PO7/HIF-1a axis

\footnotetext{
* Correspondence: riccardo.alessandro@unipa.it; simona.fontana@unipa.it

${ }^{\dagger}$ Francesca Monteleone and Simona Taverna contributed equally to this work.

'Department of Biopathology and Medical Biotechnologies - Section of

Biology and Genetics, University of Palermo, Palermo, Italy

Full list of author information is available at the end of the article
}

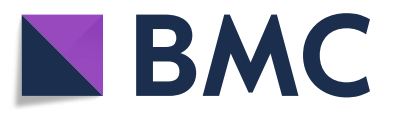

(c) The Author(s). 2018 Open Access This article is distributed under the terms of the Creative Commons Attribution 4.0 International License (http://creativecommons.org/licenses/by/4.0/), which permits unrestricted use, distribution, and reproduction in any medium, provided you give appropriate credit to the original author(s) and the source, provide a link to the Creative Commons license, and indicate if changes were made. The Creative Commons Public Domain Dedication waiver (http://creativecommons.org/publicdomain/zero/1.0/) applies to the data made available in this article, unless otherwise stated. 


\section{Background}

Chronic myelogenous leukemia (CML) is a myeloproliferative neoplasm marked by the presence of shortened Philadelphia chromosome $(\mathrm{Ph})$ that results from a reciprocal translocation between chromosome 9 and chromosome 22 [(9;22) (q34;q11)]. The molecular consequence of this translocation is the generation of $\mathrm{BCR}-\mathrm{ABL}$ fusion oncogene. The protein encoded by this fusion gene is the constitutively active tyrosine kinase $\mathrm{BCR}-\mathrm{ABL}$, which drives the malignant process in CML cells and represents the primary target of therapy [1].

Although the tyrosine kinase inhibitors (TKI) as imatinib mesylate (imatinib, Gleevec) or third generation inhibitors, are effective in controlling CML and preventing progression to blast crisis, they are not curative. Indeed, BCR-ABL transcript can be detected in patients who achieve complete cytogenetic responses [2], and the cessation of TKI therapy may result in disease relapse also in patients with undetectable level of BCR-ABL transcript [3]. These effects are due to the incapability of TKIs to eliminate leukemia stem cells (LSCs) whose survival is probably supported by kinase-independent pathways [4]. Several experimental evidences highlighted that the upregulation of hypoxia-inducible factor $1 \alpha$ (HIF-1 $\alpha)$ supports LSCs maintenance and potency [4-7], thus indicating that the identification of new drugs targeting HIF-1 $\alpha$ may be crucial for developing combined therapeutic strategies to effectively treat patients with CML.

A high number of preclinical studies have shown the relevant role that natural compounds can have in cancer prevention as well as, if used in tandem with conventional therapy, in cancer treatment [8]. Among these natural agents, curcumin, a natural polyphenol compound extracted from the rhizome of Curcuma longa, is reported to inhibit tumor growth through regulating multiple signaling pathways involved in cell proliferation, survival, apoptosis, inflammation and angiogenesis [9].

In our previous papers we demonstrated that curcumin treatment of CML cells caused a selective sorting of active miR-21 in exosomes and a concomitant decrease of this miRNA in the cells thus leading to the upregulation of PTEN that in turn caused a decrease of AKT phosphorylation and VEGF expression and release. Furthermore, we showed that addition of curcumin to CML cells caused a downregulation of BCR-ABL expression through the cellular increase of miR-196b. Moreover, we observed that animals treated with curcumin, developed smaller tumors compared to control mice and that exosomes isolated from their plasma were enriched in miR-21 [10, 11].

In this study, we employed the proteomic quantitative analytic method SWATH (Sequential Window Acquisition of all THeoretical fragment-ion spectra) [12] to examine how curcumin affected the protein profile of $\mathrm{K} 562$ cells. Our findings revealed that curcumin treatment, in
CML cells, induced an increase of several mitochondrial structural and functional proteins and a simultaneous consistent decrease of several proteins involved in glucose metabolism, most of which were HIF-1 $\alpha$ targets. According to this observation, we found that curcumin was able induce a significant reduction of HIF-1 $\alpha$ activity in comparison to untreated K562 cells. Moreover, the bioinformatics analysis of protein-expression data allowed us to identify miR-22 and its target Importin 7 (IPO7) as possible molecular mediators of the effects observed in curcumin-treated CML cells. Our findings reveal the ability of curcumin to up-regulate the expression levels of miR-22 and down-regulate the IPO7 expression, thus affecting the cytoplasm-to-nucleus shuttling of HIF-1 $\alpha$. We also demonstrated that the curcumin-induced up-regulation of miR22 may increase the intrinsic imatinib sensitivity of $\mathrm{K} 562$ cells, providing new insights for reducing excessive side effects in patients using the current fixed dosing strategy.

\section{Methods \\ Cell culture, reagents and treatments}

The human CML cell lines K562 and LAMA84 (DSMZ, Braunschweig, Germany) were cultured in RPMI 1640 medium (Euroclone, UK), supplemented with 10\% fetal bovine serum, $2 \mathrm{mM}$ L-glutamine, $100 \mathrm{U} / \mathrm{ml}$ penicillin, and $100 \mu \mathrm{g} / \mathrm{ml}$ streptomycin (Euroclone, UK).

Imatinib (Selleck) was prepared as $5 \mathrm{mM}$ stock solution in sterile phosphate-buffered saline (PBS); curcumin was prepared as $100 \mathrm{mM}$ stock solution in 0.1\% DMSO; working solutions of both curcumin and imatinib were performed in culture medium the same day of use. For the following experiments cells were treated with $20 \mu \mathrm{M}$ curcumin (Curcu-K562) and/or escalating doses of imatinib (Im-K562) for $24 \mathrm{~h}$. In the assays with curcumin, control cells (Ctrl-K562) were treated with DMSO percentage used in working solution (Ctrl-K562).

All other reagents were purchased from Sigma (St. Louis, MO), if not otherwise cited.

\section{Proteomic analyses: Sample preparation, SWATH-MS and data analysis \\ Protein extraction and digestion}

Chemicals used for protein extraction and digestion were of analytical grade, and Milli-Q water was employed in all buffers and solutions. K562 treated with only DMSO or with $20 \mu \mathrm{M}$ of curcumin (respectively Ctrl-K562 and Curcu-K562) were lysed in RIPA buffer ( $\mathrm{NaCl} 5 \mathrm{M}$, Tris $\mathrm{HCl} \mathrm{pH} 7.61 \mathrm{M}$, 5\% Triton X-100) containing protease and phosphatase inhibitors for $90 \mathrm{~min}$ in ice; lysates were centrifuged at $14000 \mathrm{~g}$ for $12 \mathrm{~min}$ at $4{ }^{\circ} \mathrm{C}$ and protein concentration was determined by Bradford method. Before performing tryptic digestion, $250 \mu \mathrm{g}$ of each cell lysate were precipitated using the 2-D Clean-Up Kit 
(Amersham) to remove Triton and other contaminants used for cell lysis; purified proteins were suspended buffer containing Tris $\mathrm{HCl}(100 \mathrm{mM})$ and urea $(8 \mathrm{M})$ and subjected to in-solution digestion. Reduction was performed with $2 \mathrm{mM}$ DTT for $30 \mathrm{~min}$ at $37^{\circ} \mathrm{C}$ and alkylation with $8 \mathrm{mM}$ IAA for $30 \mathrm{~min}$ in the dark at $37^{\circ} \mathrm{C}$. Prior to trypsin addition, sample was diluted with five-volumes of $100 \mathrm{mM} \mathrm{NH}_{4} \mathrm{HCO}_{3} \mathrm{pH}$ 8.5. Proteins were digested using $4 \mu \mathrm{g}$ of sequencing-grade modified porcine tryp$\sin$ (Pierce) $(1: 60, w / w$, trypsin to protein ratio), in presence of $2 \mathrm{mM} \mathrm{CaCl} 2$. After overnight incubation, digestion was stopped by adding $50 \mu \mathrm{l}$ of $2.5 \%$ trifluoroacetic acid (TFA). Once concentrated with a speed vacuum centrifuge, before injection, extracted peptides were desalted by solid phase extraction using C18 Macrospin Columns. C18 columns were conditioned with acetonitrile $(\mathrm{ACN})$ and rinsed with water; peptides were eluted with $70 \% \mathrm{ACN} / \mathrm{H}_{2} \mathrm{O}(70: 30, v / \mathrm{v})$ containing $0.1 \%$ formic acid (FA), and were dried, to be then re-suspended in $5 \% \mathrm{ACN} / \mathrm{H}_{2} \mathrm{O}(5: 95, \mathrm{v} / \mathrm{v})$ containing $0.1 \%$ FA. For each sample, two biological replicates were prepared and used for the following proteomic analysis.

\section{Generation of the reference spectral library}

Approximately $2 \mu \mathrm{g}$ of pooled tryptic peptides from each biological replicate of Ctrl-K562 and Curcu-K562 were subjected to Data Dependent Acquisition (DDA) analysis. The resulting list of protein/peptides was used for construction of the SWATH reference spectral library. The sample was analyzed via reverse-phase high-pressure liquid chromatography electrospray ionization tandem mass spectrometry (RP-HPLC-ESI-MS/MS) using a TripleTOF 5600 mass spectrometer (AB SCIEX; Framingham, US). The mass spectrometer was coupled to a nanoLC Eksigent 425 system (AB SCIEX; Framingham, US). RP-HPLC was performed with a trap and elution configuration using a Nano cHiPLC Trap column $200 \mu \mathrm{m} \times 0.5 \mathrm{~mm}$ ChromXP C18-CL $3 \mu \mathrm{m} 120 \AA$ and a Nano cHiPLC column $75 \mu \mathrm{m} \times 15 \mathrm{~cm}$ ChromXP C18-CL $3 \mu \mathrm{m} 120 \AA$. The reverse-phase LC solvents were: solvent $\mathrm{A}$ ( $0.1 \%$ formic acid in water) and solvent B ( $2 \%$ water and $0.1 \%$ formic acid in acetonitrile). The sample was loaded in the trap column at a flow rate of $5 \mu \mathrm{l} / \mathrm{min}$ for $10 \mathrm{~min}$ in a solvent containing $2 \%$ acetonitrile and $0.1 \% \mathrm{v} / \mathrm{v}$ TFA in water and eluted at a flow rate of $300 \mathrm{nl} / \mathrm{min}$ using the following gradient method: 1) solvent B from 10 to $28 \%$ within $120 \mathrm{~min}$ and to $60 \%$ within $30 \mathrm{~min} ; 2$ ) phase B to $95.2 \%$ within 2 min; 3) phase B decreased to $94.8 \%$ for $10 \mathrm{~min}$ (to rinse the column); 4) phase B decreased to $10 \%$ over $2 \mathrm{~min}$. Finally, the column was equilibrated for $36 \mathrm{~min}$ (200 min total run time). The eluting peptides were on-line sprayed in the Triple TOF 5600 Plus mass spectrometer, that it is controlled by Analysts 1.6.1 software (AB SCIEX, Toronto, Canada).

For DDA run, the mass range for MS scan was set to $m / z 350-1250$ and the MS/MS scan mass range was set to $m / z 230-1500$. Using the mass spectrometer, a $0.25 \mathrm{~s}$ survey scan (MS) was performed, and the top 25 ions were selected for subsequent MS/MS experiments employing an accumulation time of $0.15 \mathrm{~s}$ per MS/MS experiment for a total cycle time of $4.0504 \mathrm{~s}$. Precursor ions were selected in high resolution mode $(>30,000)$, tandem mass spectra were recorded in high sensitivity mode (resolution $>15,000$ ). The selection criteria for parent ions included an intensity of greater than $50 \mathrm{cps}$ and a charge state ranging from +2 to +5 . A $15 \mathrm{~s}$ dynamic exclusion was used. The ions were fragmented in the collision cell using rolling collision energy, and CES was set to 2 .

The DDA MS raw file was subjected to database searches using ProteinPilot ${ }^{\mathrm{tw}} 4.5$ software (AB SCIEX; Framingham, US) with the Paragon algorithm by using the following parameters: iodoacetamide cysteine alkylation, digestion by trypsin and no special factors. The search was conducted through identification efforts in a UniProt database (downloaded in July 2014, with 137,216 protein sequence entries) containing whole Homo sapiens proteins. A false discovery rate analysis was performed.

\section{SWATH-MS analysis and targeted data extraction}

The two biological replicates of Ctrl-K562 and Curcu-K562 ( $2 \mu \mathrm{g}$ each) were twice run and subjected to the cyclic data independent acquisition (DIA) of mass spectra. Data were acquired by repeatedly cycling through 34 consecutive 25-Da precursor isolation windows (swaths). For these experiments, the mass spectrometer was operated using a 0.05 s survey scan (MS). The subsequent MS/MS experiments were performed across the mass range of 350 to $1250 \mathrm{~m} / \mathrm{z}$ on all precursors in a cyclic manner using an accumulation time of $0.0898 \mathrm{~s}$ per SWATH window for a total cycle time of $3.3335 \mathrm{~s}$. Ions were fragmented for each MS/MS experiment in the collision cell using rolling collision energy, and CES was set to 15. Spectral alignment and targeted data extraction of DIA data files were performed with PeakView v.2.2 SWATH Processing MicroApp v2.0 (AB SCIEX; Framingham, US) by using the reference spectral library generated as above described. All eight DIA files were loaded in one comparison group in unison and processed as reported by $\mathrm{Li} \mathrm{H}$. et al. [13] with the following modifications: up to ten peptides/ protein and up to seven transitions/peptide. The area under the intensity curve for individual ions of a targeted peptide were summed to represent the peptide and the areas of the corresponding peptides were summed to represent the targeted proteins. These areas were used for relative quantification and statistics 
analysis. For each protein, seven individual ion intensities were summed for obtaining peptide intensity, ten peptides intensities were summed for obtaining protein intensity. The mass spectrometry proteomics data have been deposited to the ProteomeXchange Consortium (http:// proteomecentral.proteomexchange.org) [14] via the PRIDE partner repository [15] with the dataset identifier $<$ PXD007771 $>$.

\section{Statistical analysis, gene ontology analysis, functional networks and pathway mapping}

The protein list with FDR lower than $5 \%$ generated by analyzing SWATH data with PeakView 2.2, was exported to MarkerView 1.2.1 (AB SCIEX; Framingham, US) for normalization of protein intensity (peak area) using the total area sums algorithm and $t$-test analysis [13, 16]. Mean of all biological and technical replicates was used to compare proteins of Ctrl-K562 and Curcu-K562. Fold Change (FC) Curcu-K562 vs Ctrl-K562 thresholds at \pm 1.5 with a corrected $p$-value inferior to 0.05 were used to consider a protein up or down-regulated. GraphPad Prism 7.00 for Windows was used for (i) performing the $p$-value Benjamini-Yekutieli (BY-Pvalue) correction (13); (ii) to make a volcano plot scaling in which the FC was transformed using the $\log 2$ function, so that the data is centered on zero, while the BY corrected $p$-value was $-\log 10$ transformed. The Graphical Proteomics Data Explorer (GProX), a freely available complete software platform (14) was used to calculate the linear regression of repeats. The analysis of coefficients of variation for replicates was performed using Microsoft Excel 2010. The expression-based heat map was obtained by using the Heatmapper freely available web server (http:// www.heatmapper.ca). The Gene Ontology (GO) and KEGG (Kyoto Encyclopedia of Genes and Genomes) analysis of proteins up- and down-regulated following treatment with curcumin (respectively Curcu-UpRegProteins and Curcu-DownRegProteins) were initially performed using the stand-alone enrichment analysis tool FunRich (Functional Enrichment analysis tool; http:// www.funrich.org) [17]. The ClueGO v2.3.3 + CluePedia v1.3.3, a Cytoscape v3.4.0 plug-in was used to visualize the non-redundant GO terms and pathways in functionally organized networks reflecting the relations between the biological terms based on the similarity of their linked gene/proteins [18]. In order to make cluster/group comparison and highlight functional differences, the two protein groups mentioned above were uploaded in ClueGO as two separate clusters using the Cytoscape environment [19].

For the enrichment of biological terms and groups, we used the two-sided (Enrichment/Depletion) tests based on the hyper-geometric distribution. We set the statistical significance to $0.05(p \leq 0.05)$, and we used the Benjamini-Hochberg adjustment to correct the $p$-value for the terms and the groups created by ClueGO. We used fusion criteria to diminish the redundancy of the terms shared by similar associated proteins, which allows one to maintain the most representative parent or child term and the used parameters were: kappa score threshold set to 0.4; GO tree interval: 3-8; GO Term Fusion; Leading Group: Highest Significance; \% of Group Merge: 50.

Quantitative polymerase chain reaction (qPCR) for miR-22 The expression of miR-22 was tested by miScript PCR System (QIAGEN, Hilden, Germany). The RNAspin Mini (GE Healthcare Science, Uppsala, Sweden) was used to isolate total RNA from K562 and LAMA84 cells treated or not with curcumin. Reverse transcription reactions were performed using miScript II RT Kit (QIAGEN, Hilden, Germany) as described by the manufacturer's instructions. We used miScript HiSpec Buffer for cDNA synthesis to detect mature miRNA. Quantitative Real Time PCR was performed using miScript SYBR Green PCR Kit (QIAGEN, Hilden, Germany). Mature miR-22-3p (mature miRNA sequence 5'-AAGCUGCCAGUUGA AGAACUGU-3') was detected by miScript Primer Assay (MIMAT0000077; QIAGEN, Hilden, Germany) according to manufacturer's instructions. RNU6-2 was used as endogenous control. Expression levels of miRNAs were determined using the comparative $\mathrm{Ct}$ method to calculate changes in $\mathrm{Ct}$ and ultimately fold and percent change. An average $\mathrm{Ct}$ value for each RNA was obtained from triplicate reactions.

\section{qPCR for HIF-1 $a$ and IPO7}

Total cellular RNA was isolated from $\mathrm{K} 562$ and LAMA84 cells treated with curcumin using the RNAspin Mini (GE Healthcare Science, Uppsala, Sweden). For HIF- $1 \alpha$ and Importin 7 (IPO7) mRNA detection, $1 \mu \mathrm{g}$ of total RNA was reverse transcribed using the High Capacity cDNA Archive kit (Life Technologies, Carlsbad, California, U.S.), according to manufacturer's instructions. HIF- $1 \alpha$ and IPO7 transcript levels were measured by quantitative $\mathrm{SYBER}^{\circ}$ Green real time PCR; reactions were carried out in a total volume of $20 \mu \mathrm{l}$ containing $2 \times \mathrm{SYBR}^{\circ}$ Green I Master Mix (Applied Biosystems), $2 \mu \mathrm{l}$ cDNA and $300 \mathrm{nM}$ forward and reverse primers. Primers sequence were: GAPDH (5'ATGG GGAAGGTGAAGGTCG3'; 5'GGGTCATTGATGGC AACAATAT3'), HIF- $1 \alpha$ (5' TGATTGCATCTCCATCT CCTACC3'; 5'GACTCAAAGCGACAGATAACACG3') and IPO7 (5'TGGGACCTGATCATGCAACC3'; 5'AGC TGCCTTCATGACATCCC3'). All reagents were from Invitrogen (Foster City, CA, USA). Real-time PCR was performed in duplicates for each data point. Relative changes in gene expression between control and treated samples were determined with the $\Delta \Delta \mathrm{Ct}$ method. 
Changes in the target mRNA content relative to GAPDH were determined using the comparative $\mathrm{Ct}$ method as described in the previous paragraph.

\section{Transfection of K562 cells with miR-22 inhibitor}

Transfection of miScript miR-22-3p inhibitor (MIN0000077, QIAGEN, Hilden, Germany) in K562 cells (QIAGEN, Hilden, Germany) was performed according Fast-Forward Transfection protocol (QIAGEN, Hilden, Germany). $6 \times 10^{4} \mathrm{~K} 562$ cells per well were seeded in a 24-well plate in $500 \mu \mathrm{l}$ of RPMI. miScript miR-22 (2'-O-Me-miR-22) $(2 \mu \mathrm{M})$ were diluted in $100 \mu \mathrm{l}$ culture medium without serum to obtain a final $5 \mathrm{nM}$ miRNA concentration. The cells were transfected using HiPerFect Transfection Reagent (QIAGEN, Hilden, Germany) according to manufacturer's instructions for $18 \mathrm{~h}$. MiScript Inhibitor Negative Control (QIAGEN, Hilden, Germany) was used as negative control as indicated by manufacture's technical specifications. Transfection efficiency was evaluated by quantitative Real Time PCR.

\section{HIF $1 a$ transcription activation assay}

K562 and LAMA84 cells treated with $20 \mu \mathrm{M}$ of curcumin were harvested after $24 \mathrm{~h}$ of incubation. K562 cells were also transfected or not with miR-22 inhibitor. Nuclear extracts were prepared by using the Nuclear Extract Kit from Activemotif (\#40010 - Activemotif, Carlsbad, CA, USA) according to the manufacturer's instructions. The transcriptional activity of HIF- $1 \alpha$ was assayed by an ELISA-based kit (\#47096 - TransAM Kit, Activemotif, Carlsbad, CA, USA) according to the manufacturer's instructions. Nuclear extract samples were added to the coated plate and analyzed at $450 \mathrm{~nm}$ with Gen5 Microplate Collection \& Analysis Software Data (BioTek Instruments, Inc. ${ }^{\circ}$. HIF- $1 \alpha$ activity was expressed as Absorbance value.

\section{Western blot}

Total cell lysates or nuclear/cytoplasm fractions were resolved in 6 or $8 \%$ SDS-PAGE and analyzed by Western Blot. Primary antibodies used in the experiments were: anti-IPO7 (1:500; ThermoFischer), anti-HIF-1 $\alpha$ (1:1000; Millipore) and anti-actin beta (1:500; Cell Signaling Technology, Beverly, MA). Secondary antibodies (anti-mouse or anti-rabbit depending on primary antibody) were Alexa Fluor or HRP conjugated. When HRP conjugated secondary antibodies were used, protein bands were detected using Amersham ECL Western Blotting Detection Reagent; protein bands were finally visualized using Chemidoc (BioRad). The signal intensity of each band was calculated with Image J software (http:// rsbweb.nih.gov/ij/).

\section{Proliferation assay (MTT assay)}

Methyl-thiazol-tetrazolium (MTT) assay was done as previously described [20, 21]. K562 and LAMA84 cells were seeded in 96-well plates $(2-5 \times 103$ cells/well) and incubated for $24 \mathrm{~h}$ with $10,20,40 \mu \mathrm{M}$ curcumin for $24 \mathrm{~h}$.

For co-treatment experiments, K562 cells were seeded in 96-well plates $(2-5 \times 103$ cells/well $)$ and incubated for $24 \mathrm{~h}$ with $20 \mu \mathrm{M}$ curcumin (Curcu-K562) and/or escalating doses of imatinib (Im-K562). In order to assess the synergism between curcumin and imatinib on viability, both K562 and LAMA84 cells were treated for $48 \mathrm{~h}$ with curcumin alone $(5,10,20,40,50 \mu \mathrm{M})$, imatinib alone $(0.1,0.2,0.5,1$ and $5 \mu \mathrm{M})$ or imatinib + curcumin combination (imatinib at concentrations of $0.1,0.2,0.5,1$ and $5 \mu \mathrm{M} ; 20 \mu \mathrm{M}$ curcumin held constant). Cell proliferation was assessed using a MTT assay. Control cells were seeded in absence of curcumin and with appropriate percentage of DMSO. Means and standard deviations were generated from three independent experiments. Graphs and statistical analysis were performed by using Microsoft Excel 2010. For synergism determination, percent cell survival results were converted to Fraction Affected (FrAf) as follows: $\mathrm{FrAf}=0$ represents $100 \%$ viability; $\mathrm{FrAf}=1$ represents $0 \%$ viability. Imtinib + curcumin interaction was assessed by Combination Index (CI) analysis using the CompuSyn software program (ComboSyn, Inc., Paramus, NJ) based on the Chou-Talalay equation $[22,23]$. CI index of less than 1 was considered to indicate a synergistic interaction.

\section{Results}

The aim of this study was to evaluate if within the first $24 \mathrm{~h}$ of treatment a sub-toxic dose of curcumin may induce significant biological effects in CML cells in order to propose the use of this natural compound as adjuvant of canonical anti-leukemic drugs. Based on preliminary data on cell survival obtained on K562 and LAMA84 cells treated with increasing doses of curcumin (Additional file 1: Figure S1a-b), we selected the dose of $20 \mu \mathrm{M}$ of curcumin for all subsequent experiments performed within this study. The experimental design and workflow were based on application of SWATH label-free proteomics quantitative technology as illustrated in Fig. 1. A peptide mixture of both control (Ctrl-K562) and curcumin-treated K562 cells (Curcu-K562) was run using a Data-Dependent Acquisition (DDA) method in order to build the spectral library needed for the following SWATH-MS analysis. The integrated DDA data sets were searched against the Homo sapiens UniProt fasta database by using ProteinPilot 4.5 at a $1 \%$ critical false discovery rate (FDR), at both protein and peptide levels allowing the identification of 2059 proteins (the lists of identified peptides and proteins are shown in Additional file 2: Table S1, respectively in sheet 


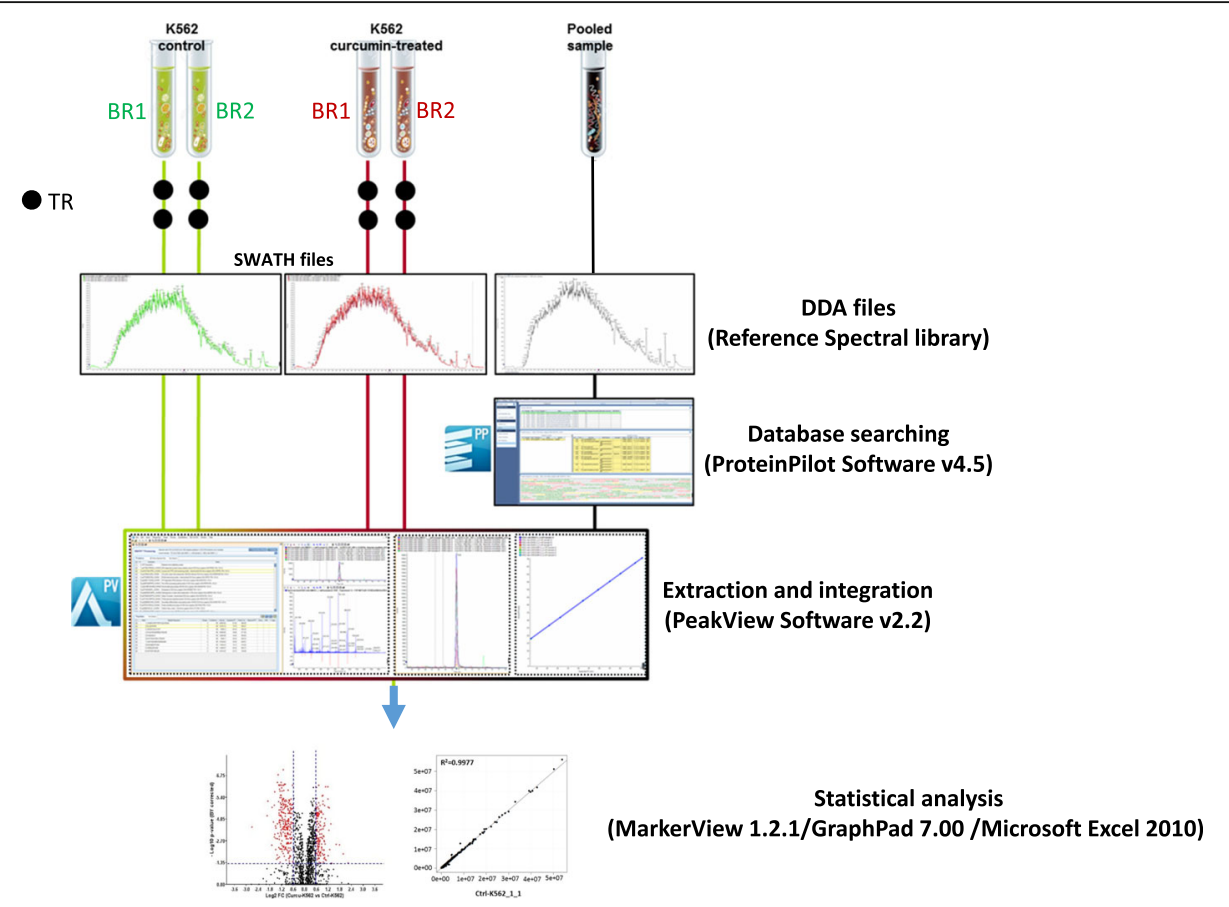

Fig. 1 Experimental design and workflow for quantitative proteomics analysis of Ctrl-K562 and Curcu-K562 cells. The SWATH-MS analysis was performed using a Triple TOF 5600+ system equipped with a Nanospray III interface and coupled to an Eksigent nanoLC 425. For quantitative analysis, $1 \mu \mathrm{g}$ of each sample was subjected to SWATH acquisition (34 swaths of $25 \mathrm{Da}$ ); two mass spectrometric technical replicates were acquired for each of the two biological replicates. To generate the spectral reference library, $2 \mu \mathrm{gg}$ of the pooled sample were subjected to traditional data-dependent acquisition (DDA). A library of 1967 proteins was created. After performing the extraction and integration processes using PeakView Software v2.2, 1796 proteins were exported into MarkerView 1.2.1 that together with GraphPad7.0 and Microsoft Excel 2010, was used for statistical analysis. BR: Biological Replicate; TR: Technical Replicate

"Spectral reference library-pept" and "Spectral reference library-prot"). More than $60 \%$ of the proteins were identified based on at least three peptides. The obtained spectral reference library was used for developing the following SWATH-MS strategy and 7852 targeted peptides (filtered using a FDR threshold of $\leq 5 \%$ over eight runs) allowed to obtain a detection rate of $75.3 \%(47,314$ of 62,816$)$ resulting in quantitative information for 1871 proteins (Additional file 3: Table S2, sheet "Total protein quantification"). The following comparative analysis was performed by using a filtered dataset of 1797 quantified proteins, in which deleted and uncharacterized proteins as well as proteins identified by only one peptide with high confidence but with less than 9 amino acids, were eliminated (Additional file 3: Table S2, sheet "Filtered protein quantification"). We found that among the technical and biological replicates, the percentage of proteins whose quantitation showed a coefficient of variation $(\mathrm{CV}) \leq 25 \%$ in the quantitative data was $90.7 \%$ for the Ctrl-K562 group and $90.8 \%$ for Curcu-K562 group (Fig. 2a and Table 1). These results highlighted that the SWATH strategy used in this study ensures high throughput and reproducibility for protein quantitation. The robustness of the analysis was further confirmed by the analysis of variance showing that the $R^{2}$ value for two repeats was never less than 0.99 in both the Ctrl-K562 group (Additional file 4: Figure S2) and Curcu-K562 group (Additional file 5: Figure S3). To identify differentially expressed proteins, a statistical analysis was applied, and proteins showing a fold change $(\mathrm{FC}) \geq \pm 1.5$ in relative abundance and a corrected BY $p$-value $<0.05$ were considered differentially modulated in untreated and curcumin-treated K562 cells (Fig. 2b). In total, by comparing Curcu-K562 vs Ctrl-K562 we found 377 proteins significantly differentially expressed that were divided in two sets: the first consisted of 143 up-regulated proteins (Additional file 3: Table S2, sheet "Curcu-UpRegProteins") and the second consisted of 234 down-regulated proteins (Additional file 3: Table S2, sheet "Curcu-DownRegProteins"). The intensity changes of the differentially expressed proteins are shown as heat map in Fig. 2c.

\section{Bioinformatic analysis for enriched terms}

To depict the functional classes significantly modulated in K562 cells treated with curcumin, the two sets of differentially expressed proteins were functionally 

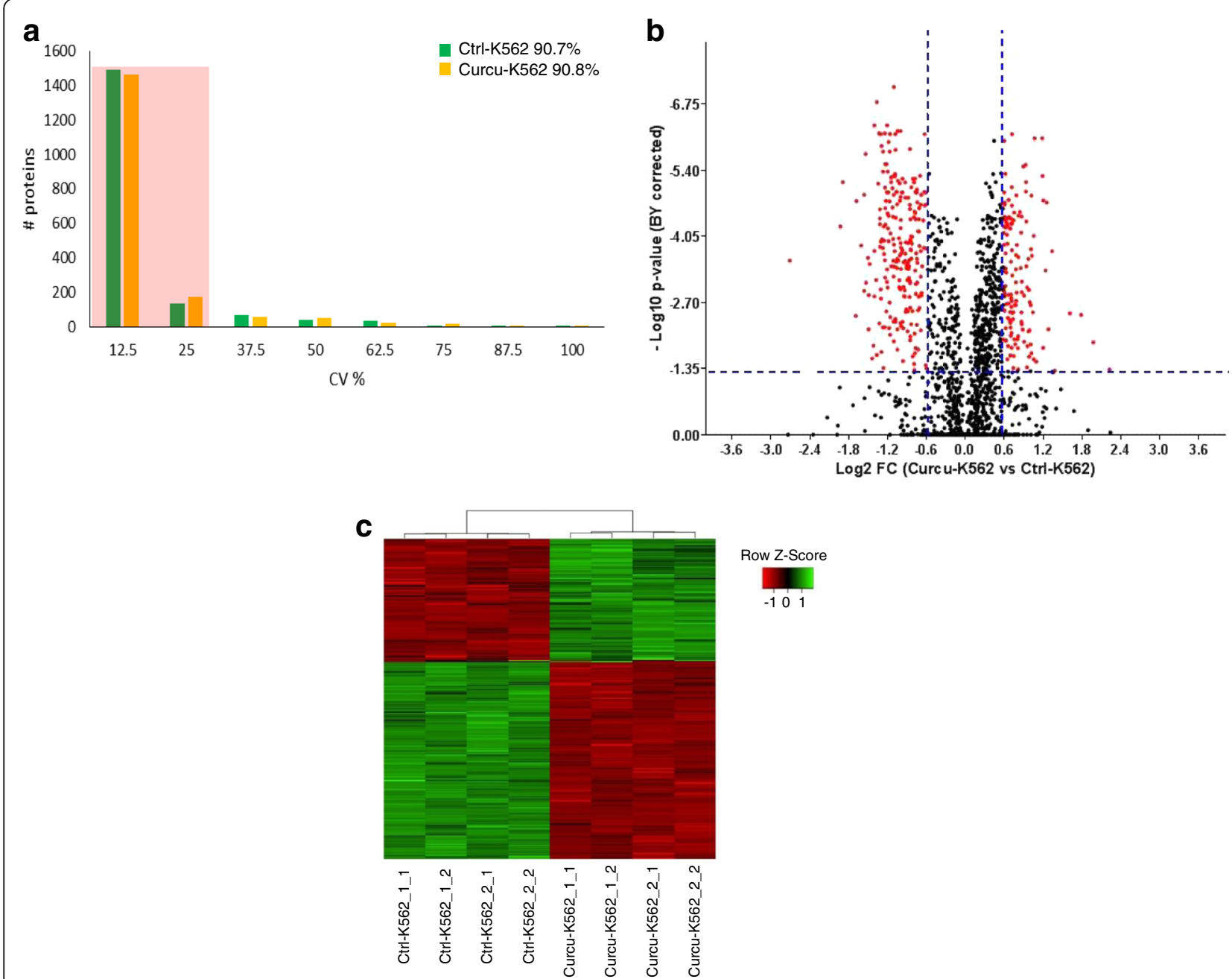

Fig. 2 Statistical analysis of SWATH data. a Histogram shows the distribution of coefficients of variation (CVs) among technical and biological replicates of Ctrl-K562 and Curcu-K562 cells. More than 90\% of the proteins as highlighted by the shadow have CV $\leq 25 \%$. b Volcano plot of 1796 quantified proteins illustrating expression increases and decreases following curcumin treatment. Red dots correspond to proteins showing a fold change (FC) $\geq \pm 1.5$ in relative abundance and a corrected BY $p$-value $<0.05$ (values indicated by vertical and horizontal dashed lines) and considered significantly differentially modulated in untreated and curcumin-treated K562 cells. c Heat map analysis of 377 modulated proteins among technical and biological replicates of Ctrl-K562 and Curcu-K562 cells. The value of the MS signal intensity is shown

Table 1 Summary of protein identification results

\begin{tabular}{|c|c|c|c|c|c|c|c|c|}
\hline \multirow[t]{3}{*}{ Samples } & \multicolumn{4}{|l|}{ Ctrl-K562 } & \multicolumn{4}{|c|}{ Curcu-K562 } \\
\hline & \multicolumn{2}{|l|}{ Ctrl-K562_1 } & \multicolumn{2}{|c|}{ Ctrl-K562_2 } & \multicolumn{2}{|c|}{ Curcu-K562_1 } & \multicolumn{2}{|c|}{ Curcu-K562_2 } \\
\hline & $\begin{array}{l}\text { Ctrl- } \\
\text { K562_1_1 }\end{array}$ & $\begin{array}{l}\text { Ctrl- } \\
\text { K562_1_2 }\end{array}$ & $\begin{array}{l}\text { Ctrl- } \\
\text { K562_2_1 }\end{array}$ & $\begin{array}{l}\text { Ctrl- } \\
\text { K562_2_2 }\end{array}$ & $\begin{array}{l}\text { Curcu- } \\
\text { K562_1_1 }\end{array}$ & $\begin{array}{l}\text { Curcu- } \\
\text { K562_1_2 }\end{array}$ & $\begin{array}{l}\text { Curcu- } \\
\text { K562_2_1 }\end{array}$ & $\begin{array}{l}\text { CurCu- } \\
\text { K562_2_2 }\end{array}$ \\
\hline Numbers of proteins in DDA protein library & \multicolumn{8}{|l|}{2061} \\
\hline Numbers of peptides in DDA protein library & \multicolumn{8}{|l|}{13616} \\
\hline $\begin{array}{l}\text { Numbers of proteins quantified in SWATH } \\
\text { analysis }\end{array}$ & \multicolumn{8}{|l|}{1801} \\
\hline $\begin{array}{l}\text { Numbers (and percentage) of quantified protein } \\
\text { with CV } \leq 25 \% \text { among technical and biological } \\
\text { replicates }\end{array}$ & \multicolumn{4}{|c|}{1629 (90.7\%) } & \multicolumn{4}{|c|}{$1632(90.8 \%)$} \\
\hline
\end{tabular}


categorized using the FunRich software, which performs a hypergeometric test for the enrichment of GO terms and pathways, followed by the Benjamini \& Hochberg (BH) method for multiple test adjustment (adjP). The comparison between the 143 up-regulated proteins and the 234 down-regulated proteins provided interesting evidence about the molecular effects induced by curcumin treatment. Histograms in Fig. 3 and the Table 2 show the most significantly enriched GO categories $\left(\operatorname{adjP} \leq 10^{-5}\right)$ for each of the three GO terms, Cellular Compartment (CC), Molecular Function (MF) and Biological Process (BP), in the sets of proteins down and up regulated in curcumin-treated K562 cells. Extended data of GO enrichment analysis is provided in Additional file 6: Table S3 and Additional file 7: Table S4.

We found that most of the proteins down-regulated by curcumin treatment were associated with cytosolic localization (Fig. 3 histogram "CC": Cytoplasm, Cytosol, Proteasome complex, Cytoskeleton, Microtubule, Proteasome regulatory particle. See Table 2 for the details of this analysis) and cytosolic functions (Fig. 3 histogram "MF": Chaperone activity, Ubiquitin-specific protease activity, Translation regulator activity, Isomerase activity; Fig. 3 histogram "BP": Protein metabolism. See Table 2 for the details of this analysis), while the group of proteins up-regulated by curcumin treatment were significantly enriched in the categories associated with mitochondrial localization (Fig. 3 histogram "CC": Mitochondrion and 5 categories related to mitochondrial membrane localization. See Table 2 for the details of this analysis) and mitochondrial activities (Fig. 3 histogram "MF": Oxidoreductase activity; Fig. 3 histogram "BP": Transport. See Table 2 for the details of this analysis).

This divergence was further confirmed by analyzing the category "metabolism", within the BP GO term. Indeed, even if this category was significantly enriched in both CurcuDown- and CurcuUp-Regulated Proteins set (Fig. 3 histogram "BP" and Table 2), the analysis of its specific composition showed the presences of functionally different proteins (as detailed in Additional file 6: Table S3 and Additional file 7: Table S4). As reported in BiolPath histograms in Fig. 3 and in Table 3, the Biological Pathway enrichment analysis revealed that the metabolic proteins down-regulated by curcumin were typically associated to glucose metabolism and that some of them were related to HIF- $1 \alpha$ transcription factor network (ALDOA; PKM; LDHA; PGK1. See Table 3), whereas metabolic proteins up-regulated by curcumin were mostly related to mitochondrial activities.

For a deeper understanding of the biological meaning and relevance of effects induced in K562 cells by curcumin treatment, we performed functional enrichment

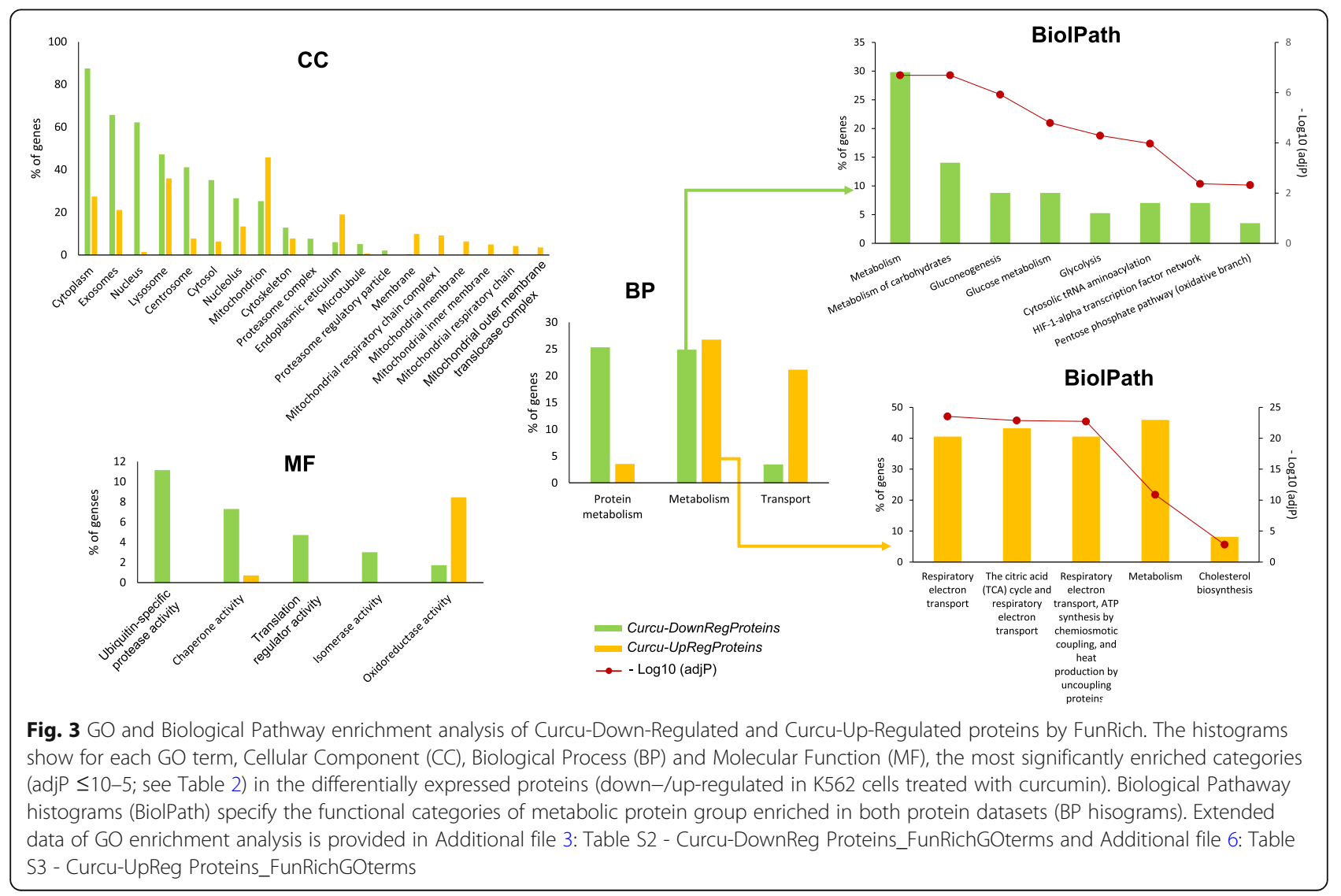


Table 2 Most significantly enriched GO categories (adjP $\leq 10^{-5}$ ) within the differentially Curcu-regulated proteins datasets

\begin{tabular}{|c|c|c|c|c|c|}
\hline GO term & $\begin{array}{l}\text { \# of proteins in } \\
\text { the dataset }{ }^{(a)}\end{array}$ & $\begin{array}{l}\text { \# of proteins in the } \\
\text { background dataset }\end{array}$ & $\begin{array}{l}\% \text { of } \\
\text { proteins }\end{array}$ & $\begin{array}{l}\text { Fold } \\
\text { enrichment }\end{array}$ & $\begin{array}{l}\text { AdjP-Value } \\
\text { (BH method) }\end{array}$ \\
\hline \multicolumn{6}{|l|}{ Cellular Component (CC) } \\
\hline \multicolumn{6}{|l|}{ Enriched in Curcu-Down-Regulated protein dataset } \\
\hline Cytoplasm & 204 & 5684 & 87.55 & 2.96 & $9.19 \mathrm{E}-75$ \\
\hline Exosomes & 153 & 2043 & 65.67 & 6.18 & 7.35E-89 \\
\hline Nucleus & 145 & 5847 & 62.23 & 2.05 & 7.44E-22 \\
\hline Lysosome & 110 & 1620 & 47.21 & 5. & $8.46 \mathrm{E}-54$ \\
\hline Centrosome & 96 & 656 & 41.20 & 12.08 & 1.64E-76 \\
\hline Cytosol & 82 & 1178 & 35.19 & 5.75 & $1.28 \mathrm{E}-38$ \\
\hline Nucleolus & 62 & 1257 & 26.61 & 4.07 & $3.99 \mathrm{E}-2$ \\
\hline Mitochondrion & 59 & 1259 & 25.32 & 3.87 & 5.61E-18 \\
\hline Cytoskeleton & 30 & 427 & 12.88 & 5.8 & $6.42 \mathrm{E}-13$ \\
\hline Proteasome complex & 18 & 34 & 7.73 & 43.7 & $3.95 \mathrm{E}-24$ \\
\hline Microtubule & 12 & 129 & 5.15 & 7.68 & $3.70 \mathrm{E}-06$ \\
\hline Proteasome regulatory particle & 5 & 8 & 2.15 & 51.62 & $9.69 \mathrm{E}-07$ \\
\hline \multicolumn{6}{|l|}{ Enriched in Curcu-Up Regulated protein dataset } \\
\hline Mitochondrion & 65 & 1259 & 45.77 & 6.99 & $1.91 \mathrm{E}-17$ \\
\hline Lysosome & 51 & 1620 & 35.92 & 4.26 & 3.69E-06 \\
\hline Endoplasmic reticulum & 27 & 1104 & 19.01 & 3.31 & 2.89E-05 \\
\hline Mitochondrial respiratory chain complex I & 13 & 46 & 9.15 & 38.29 & $2.39 \mathrm{E}-15$ \\
\hline Mitochondrial membrane & 9 & 56 & 6.34 & 21.78 & $3.73 \mathrm{E}-08$ \\
\hline Mitochondrial inner membrane & 7 & 58 & 4.93 & 16.36 & $2.22 \mathrm{E}-05$ \\
\hline Mitochondrial respiratory chain & 6 & 8 & 4.23 & 101.6 & 7.90E-10 \\
\hline Mitochondrial outer membrane translocase complex & 5 & 6 & 3.52 & 112.88 & 1.91E-08 \\
\hline \multicolumn{6}{|l|}{ Molecular Function (MF) } \\
\hline \multicolumn{6}{|l|}{ Enriched in Curcu-Down-Regulated protein dataset } \\
\hline Ubiquitin-specific protease activity & 26 & 377 & 11.16 & 5.69 & $9.80 \mathrm{E}-11$ \\
\hline Chaperone activity & 17 & 126 & 7.30 & 11.14 & 4.68E-11 \\
\hline Translation regulator activity & 11 & 101 & 4.72 & 9 & 2.97E-06 \\
\hline Isomerase activity & 7 & 45 & 3 & 12.85 & $6.02 \mathrm{E}-05$ \\
\hline \multicolumn{6}{|l|}{ Enriched in Curcu-Up Regulated protein dataset } \\
\hline Oxidoreductase activity & 12 & 161 & 8.45 & 10.1 & 5.99E-07 \\
\hline \multicolumn{6}{|l|}{ Biological Process (BP) } \\
\hline \multicolumn{6}{|l|}{ Enriched in Curcu-Down Regulated protein dataset } \\
\hline Protein metabolism & 59 & 1323 & 25.32 & 3.68 & $1.24 \mathrm{E}-16$ \\
\hline Metabolism & 58 & 1683 & 24.89 & 2.84 & $9.15 \mathrm{E}-12$ \\
\hline \multicolumn{6}{|l|}{ Enriched in Curcu-Up Regulated protein dataset } \\
\hline Metabolism & 38 & 1683 & 26.76 & 3.06 & $2.22 \mathrm{E}-08$ \\
\hline Transport & 30 & 1215 & 21.13 & 3.34 & 2.32E-07 \\
\hline
\end{tabular}

(a) The Curcu-Up-Regulated protein dataset is composed by 233/234 proteins since the protein Q5HYB6_HUMAN (Gene Name: DKFZp686J1372) was not mapped in FunRich database; the Curcu-Up-Regulated protein dataset is composed by 142/143 proteins since the protein CD97_HUMAN (Gene name: CD97) was not mapped in FunRich database; (b) The background dataset (in FunRich database) is composed by 19,230 genes/proteins

analysis using ClueGO+CluePedia, a Cytoscape plug, which facilitates the visualization of functionally related genes/proteins displaying them as a clustered network
[18]. The statistical test used for the enrichment analysis was based on right-sided hypergeometric option with a Benjamini-Hochberg correction, kappa score of 0.4 and 
Table 3 Biological Pathway enrichment analysis of "metabolic" proteins down-regulated and up-regulated by curcumin

\begin{tabular}{|c|c|c|c|}
\hline Biological pathway & $\begin{array}{l}\% \text { of } \\
\text { proteins }\end{array}$ & $\begin{array}{l}\text { AdjP-Value } \\
\text { (BH method) }\end{array}$ & Proteins \\
\hline \multicolumn{4}{|l|}{ Curcu-Down-Regulated "metabolic" proteins } \\
\hline Metabolism & 29.82 & $2.04 \mathrm{E}-07$ & $\begin{array}{l}\text { TALDO1; ARG2; GSTP1; AHCY; TXN; FASN; TKT; COX6B1; } \\
\text { GMPS; PAICS; HPRT1; CAD; ATIC; GSTO1; ACLY; GOT1; TK1; }\end{array}$ \\
\hline Metabolism of carbohydrates & 14.04 & $2.04 \mathrm{E}-07$ & TPI1; TALDO1; GPI; MDH1; PGK1; TKT; PGD; GOT1; \\
\hline Gluconeogenesis & 8.77 & 1.19E-06 & TPI1; GPI; MDH1; PGK1; GOT1; \\
\hline Glucose metabolism & 8.77 & 1.60E-05 & TPI1; GPI; MDH1; PGK1; GOT1; \\
\hline Glycolysis & 5.26 & $5.13 \mathrm{E}-05$ & TPI1; GPI; PGK1; \\
\hline Cytosolic tRNA aminoacylation & 7.02 & 1.07E-04 & DARS; PPA1; VARS; YARS; \\
\hline HIF-1-alpha transcription factor network & 7.02 & $4.28 \mathrm{E}-03$ & ALDOA; PKM; LDHA; PGK1; \\
\hline Pentose phosphate pathway (oxidative branch) & 3.51 & $4.78 \mathrm{E}-03$ & G6PD; PGD; \\
\hline \multicolumn{4}{|l|}{ Curcu-Up-Regulated "metabolic" proteins } \\
\hline Respiratory electron transport & 40.5 & $3.0 \mathrm{E}-24$ & $\begin{array}{l}\text { UQCRC1; CYC1; COX5B; NDUFS1; NDUFA5; NDUFB4; NDUFV1; } \\
\text { UQCRH; NDUFA9; UQCRB; MT-ND5; NDUFB6; NDUFB5; NDUFB3; } \\
\text { NDUFB9; }\end{array}$ \\
\hline $\begin{array}{l}\text { The citric acid (TCA) cycle and respiratory electron } \\
\text { transport }\end{array}$ & 43.2 & $1.4 \mathrm{E}-23$ & $\begin{array}{l}\text { UQCRC1; CYC1; COX5B; NDUFS1; NDUFA5; NDUFB4; NDUFV1; } \\
\text { UQCRH; NDUFA9; UQCRB; MT-ND5; NNT; NDUFB6; NDUFB5; } \\
\text { NDUFB3; NDUFB9; }\end{array}$ \\
\hline $\begin{array}{l}\text { Respiratory electron transport, ATP synthesis by } \\
\text { chemiosmotic coupling, and heat production } \\
\text { by uncoupling proteins. }\end{array}$ & 40.5 & $1.9 \mathrm{E}-23$ & $\begin{array}{l}\text { UQCRC1; CYC1; COX5B; NDUFS1; NDUFA5; NDUFB4; NDUFV1; } \\
\text { UQCRH; NDUFA9; UQCRB; MT-ND5; NDUFB6; NDUFB5; NDUFB3; } \\
\text { NDUFB9; }\end{array}$ \\
\hline Metabolism & 45.9 & $1.4 \mathrm{E}-11$ & $\begin{array}{l}\text { UQCRC1; CYC1; COX5B; NDUFS1; NDUFA5; NDUFB4; NDUFV1; } \\
\text { CYP51A1; UQCRH; NDUFA9; UQCRB; MT-ND5; NNT; NDUFB6; } \\
\text { NDUFB5; NDUFB3; NDUFB9; }\end{array}$ \\
\hline Cholesterol biosynthesis & 8.1 & $1.5 \mathrm{E}-03$ & FDFT1; CYP51A1; DHCR24; \\
\hline
\end{tabular}

a $p$-value $<0.05$ was used as the cut-off criterion. The functional networks reported in Fig. 4 depict the results obtained by performing the enrichment analysis of KEGG pathway of CurcuUp-Regulated proteins (Fig. 4a) and Biological Process (BP) of CurcuDown-Regulated proteins (Fig. 4b). This analysis (detailed in Additional file 8: Table S5), highlighted that within the group of CurcuUpRegulated proteins seven GO Groups (nodes with the same color form a unique GO group) were enriched and among them two were constituted by multiple GO terms associated with mitochondrial structure and functions (Fig. 4a and Additional file 8: Table S5, sheet "Curcu-UpRegProt ClueGo"). In contrast, we found that within the set of Curcu-down regulated proteins 14 GO groups were significantly enriched and 50\% (7/14) were specifically associated and correlated to carbohydrate metabolism such as Pentose phosphate pathway, Glycolysis/Gluconeogenesis, Central carbon metabolism in cancer, Amino sugar and nucleotide sugar metabolism, Pyruvate metabolism, Cysteine and methionine metabolism and Purine metabolism (Fig. 4b and Additional file 8: Table S5, sheet "Curcu-DownRegProt_ClueGo"). Interestingly, some proteins, belonging to the Glycolysis/Gluconeogenesis GO group, were also indicated as specifically involved in the HIF- $1 \alpha$ signaling pathways. Together, these results clearly demonstrate that curcumin-treatment induces alterations of metabolic activities characterizing CML cells and strongly related to the activity of HIF-1 $\alpha$ pathway, known to have a critical role in in the pathogenesis of CML $[4,6,7]$.

\section{Effects of curcumin on HIF-1a activity and IPO7 expression}

HIF-1 $\alpha$ is the master regulator of cell response to hypoxic stress. However, it was reported that high levels of BCR-ABL expression correlate with a non-hypoxic induction of HIF-1 $\alpha$ [7]. We found that in K562 cells curcumin elicited a significant decrease of HIF- $1 \alpha$ activity (Fig. 5a) but without affecting its expression both at mRNA and protein level (Fig. 5b).

Transcription factors such as HIF- $1 \alpha$, to be functional and to activate transcription of target genes have to be imported from the cytoplasm to the nucleus through the nuclear pore complex (NPC). Importins, that are members of the $\beta$-karyopherin family, are nucleocytoplasmic factors that mediate nuclear import of proteins [24]. Intracellular distribution of HIF-1 $\alpha$ requires a finely regulated balance between nuclear import and export. Consequently, the reduction of HIF- $1 \alpha$ activity observed in $\mathrm{K} 562$ cells treated with curcumin, led us to hypothesize that curcumin may act by blocking the 


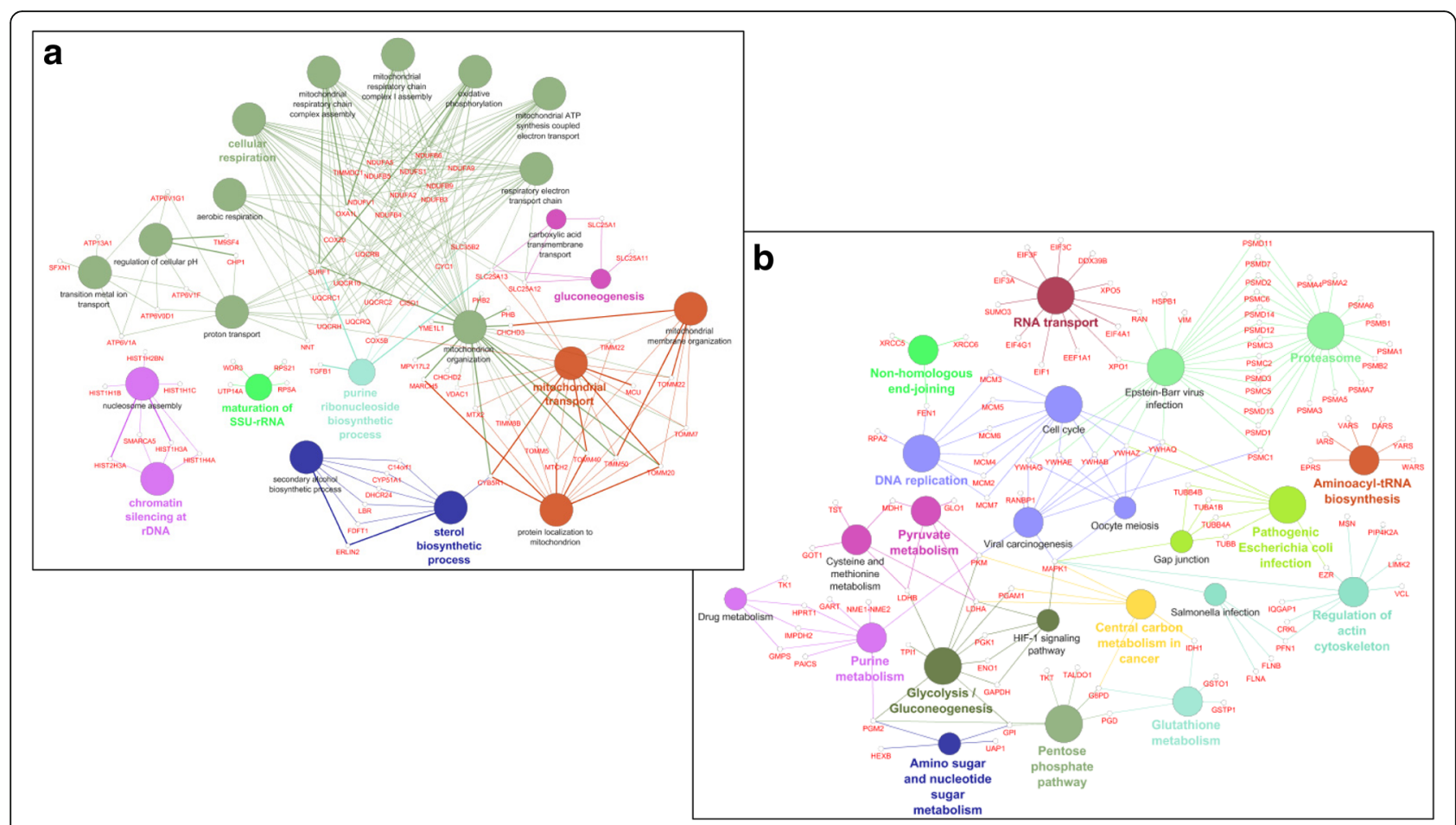

Fig. 4 Enriched GO network groups using ClueGO/CluePedia-based enrichment. a Network view for KEGG pathway of CurcuUp-Regulated proteins and $\mathbf{b}$ Biological Process of CurcuDown-Regulated proteins. Terms (each represented as node) are functionally grouped based on shared genes (kappa score $\geq 0.4$ ) and are shown with different colors. The specific players (proteins) of each node are highlighted with the respective gene name Node color represents the class that they belong. The size of the nodes indicates the degree of significance. Within each class, the most significant term (indicated with colored and bold characters) defines the name of the group. Ungrouped terms are not shown

nuclear translocation of HIF-1 $\alpha$. Interestingly, in our protein dataset we found several proteins involved in nucleocytoplasmic transport (Table 4). Even if in cells treated with curcumin all these proteins showed a general down-regulation, based on the FC and corrected $p$-value cutoffs we used in this study, just four of these proteins could be considered significantly modulated by curcumin treatment: IPO5 (FC: -1.530; BY-Pvalue: 0.0383), IPO7 (FC: -2.332; BY-Pvalue: 0.0030); TNPO1 (FC: -1.801; BY-Pvalue: 0.0099), XPO1 (FC: -1.804; BY-Pvalue: 0.0026). In particular, it was described that importin 7 (IPO7), together with importin 4 (IPO4), is able to regulate the nuclear localization of HIF-1 $\alpha$ [25]. Curcumin-induced IPO7 down-regulation highlighted by proteomic analysis was validated at both mRNA and protein level by real-time PCR (Fig. 5c) and Western blot (Fig. 5d) analyses. This data suggests that the mechanism through which the curcumin treatment induced in K562 cells a reduction of HIF- $1 \alpha$ activity may be due to the reduction of its nuclear import rate.

Analogous effects of curcumin treatment on HIF- $1 \alpha$ expression and activity as well as on IPO7 expression were also observed in LAMA84 cells (Additional file 9: Figure S4a-d).
Interestingly, we found that in both K562 and LAMA84 cells the down-regulation of HIF- $1 \alpha$ activity induced by curcumin coincided with its reduced nuclear localization (Additional file 10: Figure S5).

\section{Curcumin inhibits IPO7 expression through the activation of miR-22}

Since several studies showed that curcumin exerts its anti-cancer effect by regulating the expression of microRNAs (miRs) [26], we utilized miR target prediction software miRSearch V3.0 [27] to determine if IPO7 is subject to regulation by miRs. This analysis showed that IPO7 is a validated target of miR-22 and miR-9 [28, 29] (Additional file 11: Figure S6a). In particular we focused our attention on miR-22 since further analysis of predicted multiple targets performed by MicroRNA Target prediction (miRTar) tool (http://mirtar.mbc.nctu.edu.tw/human/) revealed that, within the dataset of CurcuDown-Regulated proteins beside IPO7 there were several miR-22 targets (Additional file 11: Figure S6b), while no targets of miR-9 were found. Moreover, a direct ability of curcumin to up-regulate miRNA-22 expression has been described [30-33]. To evaluate whether in our cell model miR-22 was modulated by curcumin treatment, we performed a 


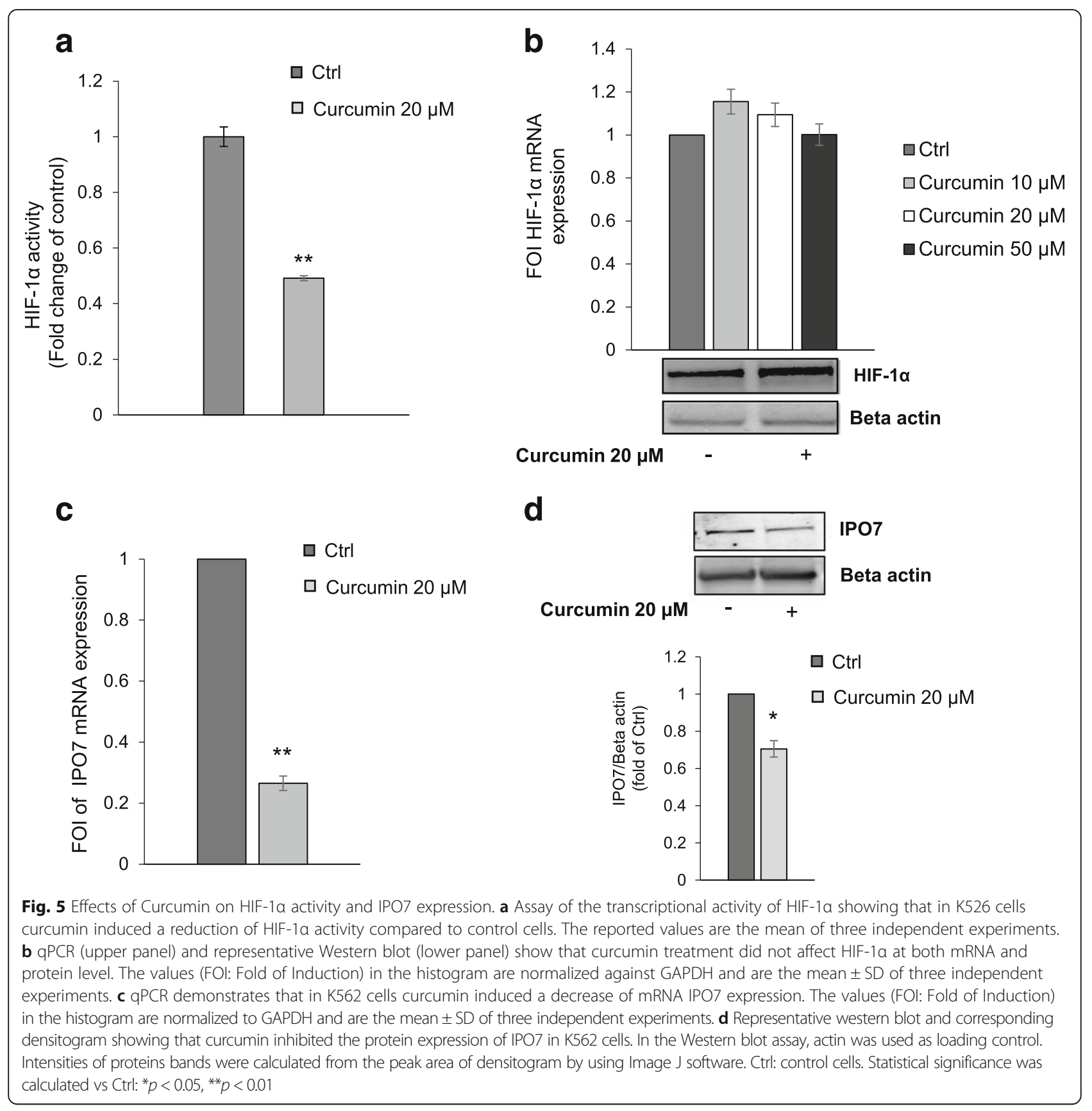

qRT- PCR on control and curcumin-treated K562 cells. We found that in cells treated with curcumin, miR-22 was about 10-fold up-regulated in comparison to control cells and the reduction of miR-22 expression in K562 cells transfected with miR-22 inhibitor was recovered when cells were simultaneously treated with curcumin (Fig. 6a). According to this result, we also observed that the expression of IPO7 (at both mRNA and protein level) observed in K562 cells transfected with miR-22 inhibitor, was significantly reduced when cells were contemporarily treated with curcumin (Fig. $6 \mathrm{~b}$ and $\mathrm{c})$. Finally, in order to test if the axis miR-22/
IPO7 could be correlated with the decrease of HIF- $1 \alpha$ activity induced by curcumin, we performed a HIF- $1 \alpha$ activity assay in $\mathrm{K} 562$ cells transfected with miR-22 inhibitor treated or not with curcumin. We found that the level of HIF- $1 \alpha$ activity observed in K562 cells transfected with miR-22 inhibitor (comparable to the control), was significantly decreased when cells were in parallel treated with curcumin, suggesting that curcumin was able to counteract the miR-22 inhibition (Fig. 6d).

Analogous effect of curcumin treatment on miR-22 expression was observed in LAMA84 cells (Additional file 9: Figure S4e). 
Table 4 Proteins implicated in nuclear import/export identified by MS in K562cells

\begin{tabular}{|c|c|c|c|c|c|c|}
\hline $\begin{array}{l}\text { UniProt Accession } \\
\text { Number }\end{array}$ & $\begin{array}{l}\text { UniProt Entry } \\
\text { Name }\end{array}$ & $\begin{array}{l}\text { Gene } \\
\text { Name }\end{array}$ & Protein Name & $\begin{array}{l}\text { Fold Change } \\
\text { (Curcu-K562 vs Ctrl K562) }\end{array}$ & $p$-Value & BY-Pvalue \\
\hline 000410 & IPO5_HUMAN & IPO5 & Importin-5 & -1.530 & 0.002162 & 0.0383 \\
\hline 095373 & IPO7_HUMAN & IPO7 & Importin-7 & -2.332 & 0.000107 & 0.0030 \\
\hline Q96P70 & IPO9_HUMAN & IPO9 & Importin-9 & -2.241 & 0.121934 & $>0.999$ \\
\hline P52292 & IMA1_HUMAN & KPNA2 & Importin subunit alpha-1 & -1.040 & 0.040815 & 0.5065 \\
\hline 000629 & IMA3_HUMAN & KPNA4 & Importin subunit alpha-3 & -1.279 & 0.002692 & 0.0465 \\
\hline 000505 & IMA4_HUMAN & KPNA3 & Importin subunit alpha-4 & -1.667 & 0.086100 & 0.9772 \\
\hline Q14974 & IMB1_HUMAN & KPNB1 & Importin subunit beta-1 & -1.114 & 0.000088 & 0.0026 \\
\hline Q92973 & TNPO1_HUMAN & TNPO1 & Transportin-1 & -1.801 & 0.00045 & 0.0099 \\
\hline E9PFH4 & E9PFH4_HUMAN & TNPO3 & Transportin-3 & -1.875 & 0.221323 & $>0.999$ \\
\hline 014980 & XPO1_HUMAN & XPO1 & Exportin-1 & -1.804 & 0.000086 & 0.0026 \\
\hline P55060 & XPO2_HUMAN & CSE1L & Exportin-2 & -1.530 & 0.011327 & 0.1659 \\
\hline Q9HAV4 & XPO5_HUMAN & XPO5 & Exportin-5 & -1.698 & 0.000021 & 0.0008 \\
\hline P12270 & TPR_HUMAN & TPR & Nucleoprotein TPR & -1.121 & 0.001823 & 0.0330 \\
\hline Q9UKX7 & NUP50_HUMAN & NUP50 & Nuclear pore complex protein Nup50 & 1.334 & 0.246 & $>0.999$ \\
\hline
\end{tabular}

Proteins considered significantly modulated by curcumin treatment (Fold Change $\geq 1.5$ and BY-Pvalue $\leq 10^{-5}$ ) are in bold

Curcumin enhances the sensitivity of K562 cells to imatinib In order to assess whether curcumin-induced modulation of miR-22 was able to impact on K562 cells sensitivity to imatinib (IM), we evaluated the cell viability by treating cells for $24 \mathrm{~h}$ with curcumin and miR-22 inhibitor alone or in co-treatment with increasing doses of IM. As indicated in Fig. 7, curcumin that already alone induces a significant cell viability reduction of about $10 \%$, is clearly able to increase the IM effectiveness for each of tested dose. In both histogram and table in Fig. 7 it is possible to observe that the addition of curcumin to IM treatment, induced a significant decrease of cell viability compared to treatment with IM alone. To note that compared to the effect of $1 \mu \mathrm{M}$ of IM alone (75\% of cell viability) both doses of $0.2 \mu \mathrm{M}$ and $0.5 \mu \mathrm{M}$ IM in co-treatment with curcumin elicited a significantly stronger negative effect on cell growth (respectively 64\% - $p$-value $=0.013$ and $53 \%$ $p$-value $=0.015$; Fig. 7). Interestingly, we noted in K562 cells transfected with miR-22 a low-level but significant resistance to $0.2 \mu \mathrm{M}$ and $0.5 \mu \mathrm{M}$ IM that was completely reverted when cells were co-treated with curcumin (Fig. 7 ). This data confirmed our hypothesis that curcumin effects are miR-22-mediated. Moreover, combination index (CI) analysis [22, 23] assessed by using a non-constant ratio of curcumin and imatinib (Additional file 12: Figure S7) showed that curcumin and imatinib have a synergistic effect on inhibition of both K562 and LAMA cell proliferation. CI results showed synergism especially when curcumin was used with lower doses of imatinb.

\section{Discussion}

Nutraceuticals play an increasingly important role in the cancer management [8]. Among them curcumin, a natural polyphenol extracted from Curcuma longa L., has been shown to have pleotropic anti-cancer properties (anti-oxidant, anti-inflammatory, anti-proliferative) inhibiting multiple targets and molecular pathways such as NF-kB, STAT3, MAPK, PTEN, P53, AKT/mTOR, VEGF and microRNAs (miRNA) network involved in cancer pathogenesis [9, 11, 34, 35]. Data accumulated in the last years has revealed that curcumin is a promising pharmacologically safe anti-tumor agent that can function as chemosensitizer and a multi-targeted inhibitor. However, actually the use of curcumin as therapeutic remedy is strongly limited by its extremely low solubility in water and in organ fluids, which subsequently limits the bioavailability and therapeutic effects of curcumin. Currently, continuous attempts are going to improve solubilization and bioavailability of this promising agent. For example it has been demonstrated that heat and pressure can significantly improve solubility of curcumin maintaining its therapeutic properties [36-39].

The benefits of curcumin have been demonstrated also in blood cancer. In acute lymphoblastic leukemia Philadelphia chromosome-positive ( $\mathrm{Ph}+\mathrm{ALL})$, it was demonstrated that curcumin potentiated the efficiency of imatinib by inhibiting the activation of the AKT/mTOR signaling and by down-regulating the expression of the BCR/ABL gene [40]. Similarly in CML it was demonstrated that curcumin treatment induced the decrease of BCR-ABL expression at both mRNA and protein level associated to a dose-dependent increase of PTEN and a decreased AKT phosphorylation and VEGF expression due to a selective packaging of miR-21 in exosomes [11].

In the present study, for the first time, we demonstrated that in CML cells curcumin at sub toxic dose affects the 


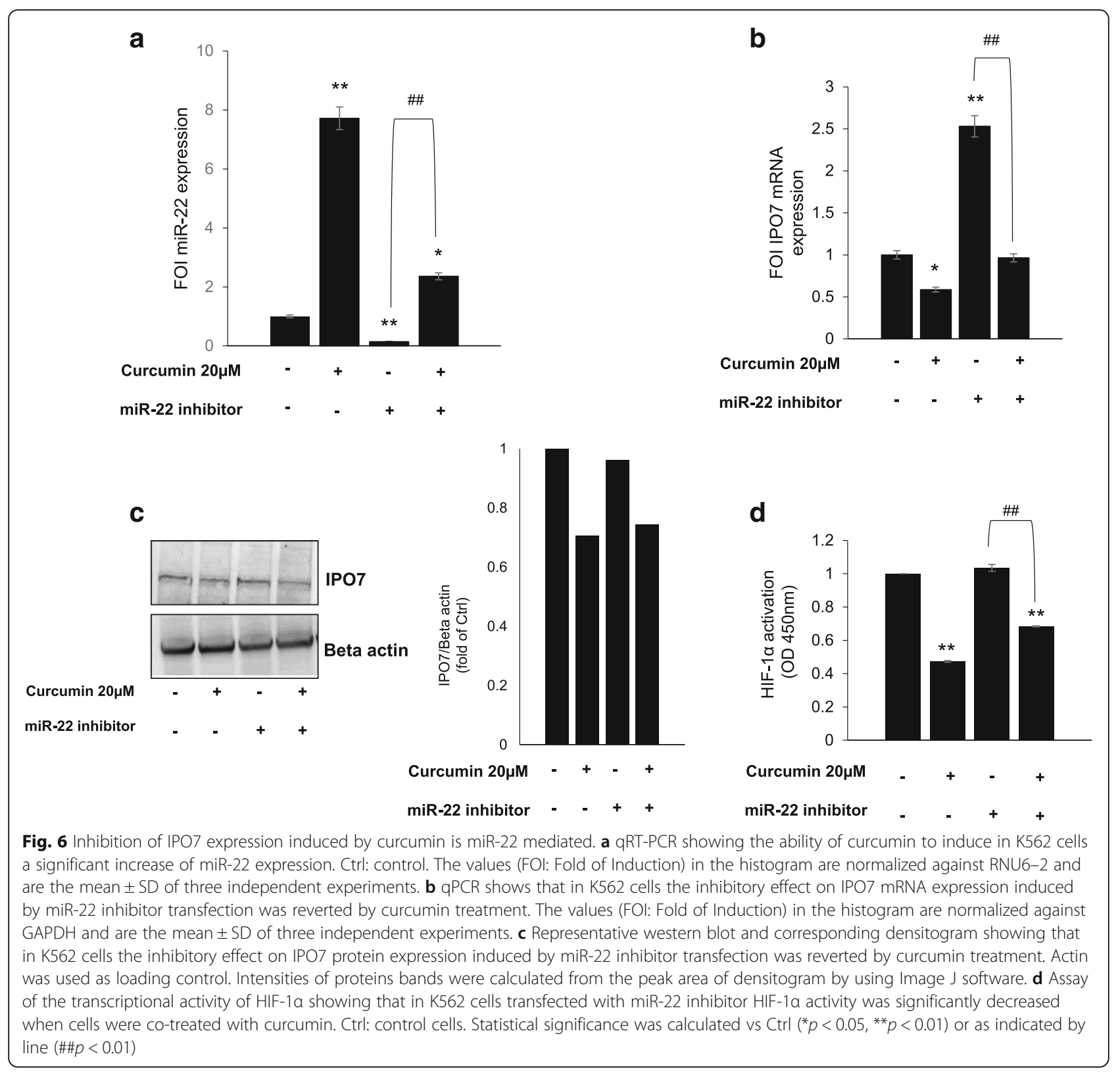

HIF-1 $\alpha$ pathway that it is known to promote leukemic cell proliferation and to play a key role in the progressive loss of sensitivity to imatinib [5-7].

We have applied SWATH-MS (sequential window acquisition of all theoretical spectra-mass spectrometry)-based quantitative proteomic analysis to examine the effect of curcumin on proteome of K562 cells, that our previous data indicated to have an intrinsic resistance to imatinib, likely related to the expression of several proteins implicated in drug resistance and with anti-apoptotic activity [41]. We found that in CML cells curcumin induced, compared to the untreated condition, a remarkable down-regulation of proteasome activity, as described in literature [42, 43], and of proteins associated to carbohydrate metabolism. In particular, we found that several enzymes involved in glycolysis/gluconeogenesis (TPI1; GPI; MDH1; PGK1; GOT1), in oxidative branch of pentose phosphate pathway (G6PD; PGD) and some direct targets of HIF-1 $\alpha$ (ALDOA; PKM; LDHA; PGK1) were down-regulated in response to curcumin treatment. The dependence of cancer cells on glycolysis process for energy production rather than oxidative phosphorylation, is so frequent and common in majority, if not, all types of tumors, to be considered as a molecular signature of cancer [44-46]. This tumor glycolysis, associated to more aggressive tumor phenotype, is directly controlled by major signal transduction pathways involved in oncogenesis often associated with HIF-1 $\alpha$ activity $[47,48]$. In CML 


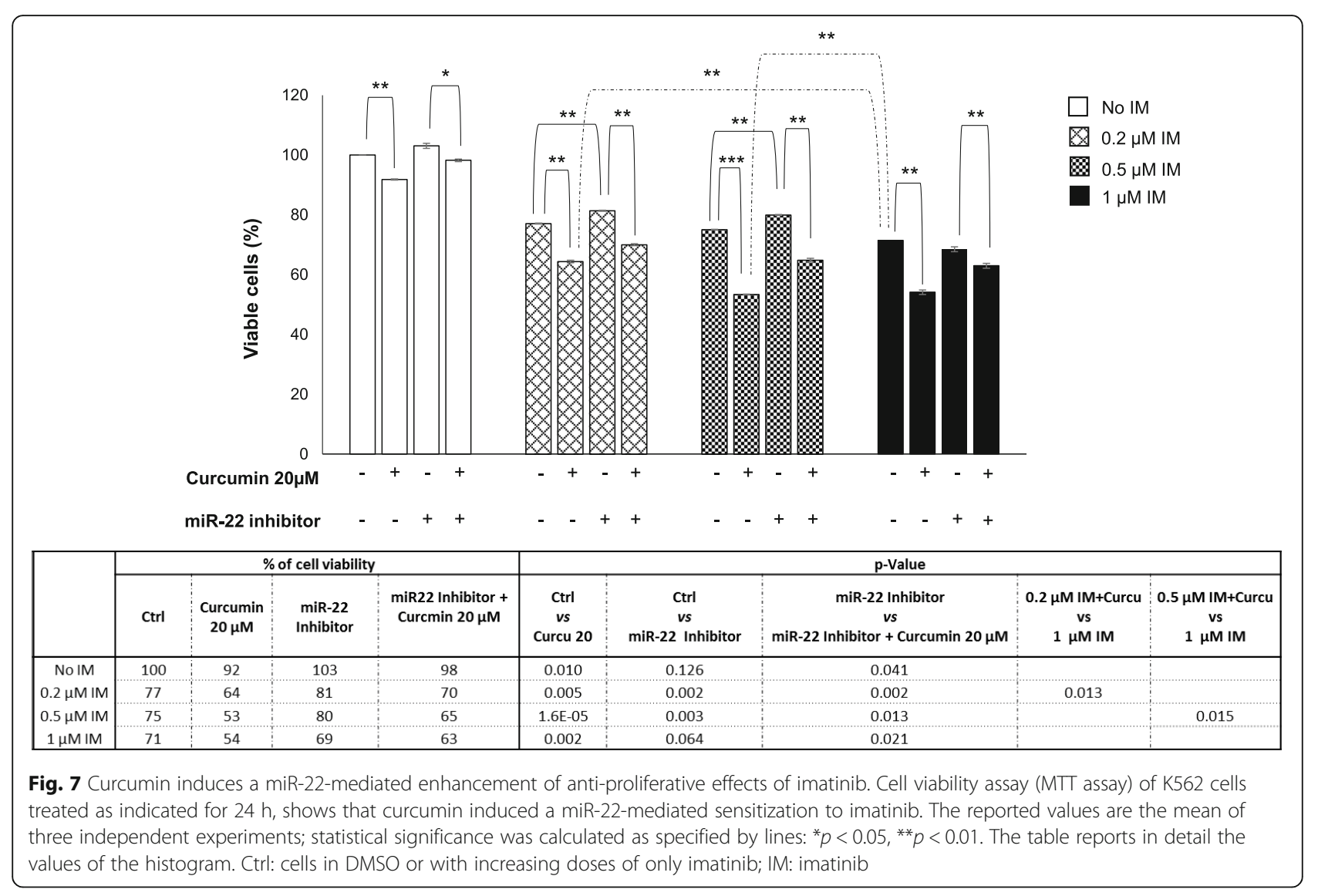

cells, in particular, increased glycolytic activity has been found to depend on the non-hypoxic activation of HIF- $1 \alpha$ and has been described as marker for early detection of imatinib resistance, before clinical manifestations [7, 49]. Moreover, data from literature has provided strong evidence in support of the crucial role of HIF-1 $\alpha$ in the pathogenesis of CML, by promoting cell proliferation and survival maintenance of LSCs [5-7]. Thus, the co-suppression of BCR-ABL and HIF- $1 \alpha$ can offer the opportunity to develop a rational therapeutic strategy for CML eradication.

Consistent with the obtained proteomic data evidencing the down-regulation of several HIF- $1 \alpha$ targets and associated pathways, we found that in K562 cells curcumin induced a decrease of HIF- $1 \alpha$ activity. Previous studies have demonstrated that the anti-cancer properties of curcumin may be related to its ability to affect the HIF-1 pathway, affecting the expression of HIF-1 $\alpha$ or by degrading ARNT (HIF1 $\beta$ ) but without altering the expression and the transcriptional activity of HIF- $1 \alpha[50,51]$. Interestingly, in the present study we found that in CML cells curcumin induced a significant inhibition of HIF- $1 \alpha$ activity, without affecting its expression. These observations led us to hypothesize that curcumin could have an indirect effect on HIF-1 $\alpha$.
Data from literature reported that curcumin is able to affect nuclear traffic by inhibiting CRM1 (exportin1 or Xpo1) [52], that we also found down-regulated in curcumin-treated K562 cells together with other proteins implicated in nuclear import/export (in total 14 of these proteins were identified in our dataset). Interestingly among them there was IPO7, an importin specifically related to HIF- $1 \alpha$ nuclear translocation [25]. According to literature data strongly supporting the ability of curcumin to regulate miRNA expression [11, $26,31,33,34]$, we found that in K562 cells the curcumin-dependent down-regulation of $\mathrm{IPO} 7$ was miR-22-mediated. To deeper define the molecular steps through which the HIF- $1 \alpha / \mathrm{miR} 22 / \mathrm{IPO} 7$ axis mediates the curcumin effects on CML cells future research can be aimed to define the timing in which HIF- $1 \alpha$ nuclear localization is modulated as well as to identify other interactors acting within this system.

Evidence accumulated in recent years has defined the key role of nuclear transport in regulating the features of cancer cells and highlighted the potential role of nuclear transport proteins as new therapeutic targets for developing combination treatment strategies [24]. For example, the ability of XPO1 inhibitors to enhance the therapeutic effects of some 

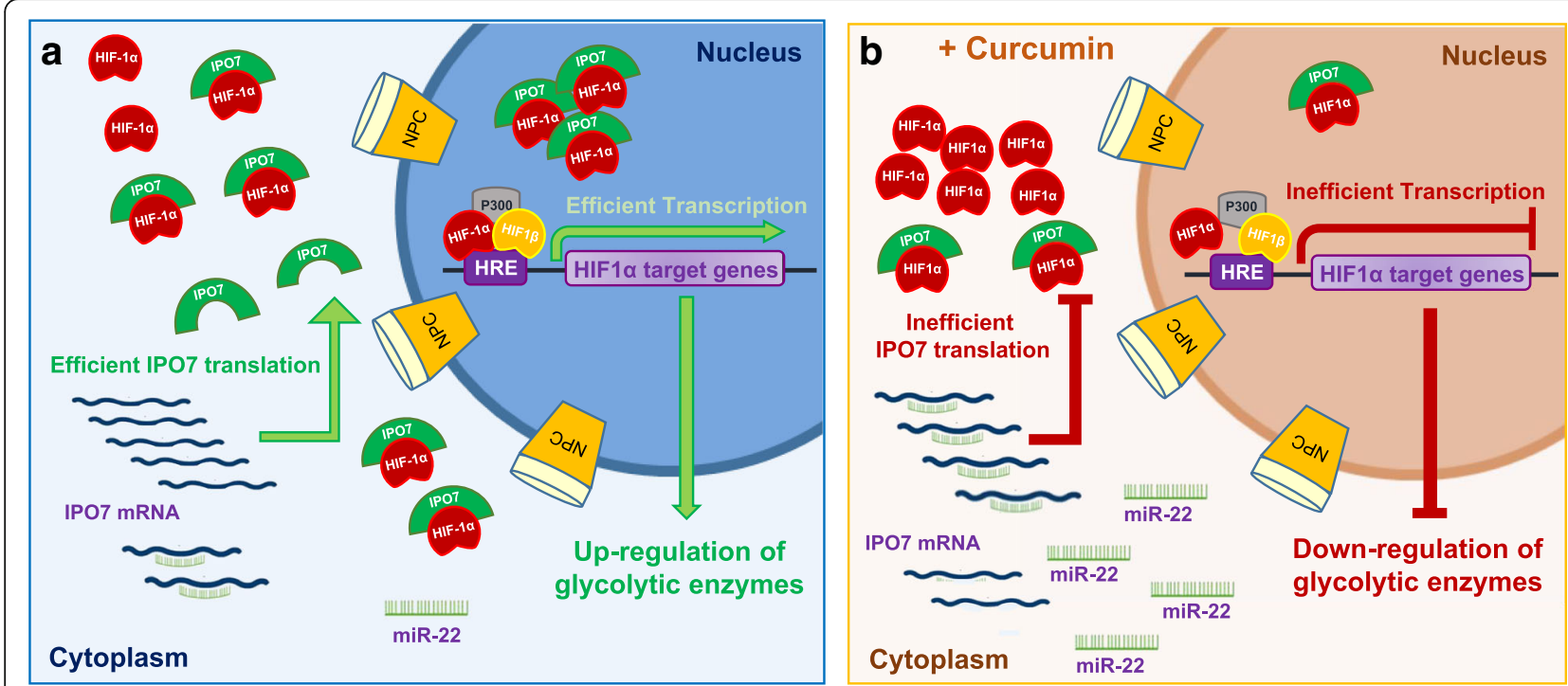

Fig. 8 The proposed model of miR-22/IPO7/HIF-1a axis modulation induced by curcumin in CML. a In basal condition CML cells are characterized by an efficient HIF-1a activity responsible of active transcription of several target genes some of which associated to glycolytic metabolism. b Curcumin by inducing up-regulation of miR-22 elicits the inhibition of IPO7 expression, hindering the HIF-1a translocation and causing the global down-regulation of glycolytic enzymes as highlighted by our quantitative proteomic data. NCP: Nuclear Pore Complex

available chemotherapeutic agents used for treating both haematological and solid tumours was reported [53-55]. Interestingly, we found that through its miR-22-mediated activity, curcumin on K562 cells enhanced the anti-proliferative effects of imatinib. This finding adds new evidence about the molecular mechanisms through which curcumin can enhance the efficacy of anti-cancer drugs working as chemosensitizer [43, 56, 57]. From a clinical point of view this is an interesting data since it is widely recognized that during treatment with imatinib, dose optimization proved an effective tool to reach adequate response by improving efficacy and reducing toxicity and costs of treatment [58].

\section{Conclusions}

In conclusion, our data highlighted that in CML cells curcumin, beyond its well-known ability to inhibit the proteasome pathway [42, 43], activates alternative molecular networks affecting the glycolytic metabolism that in CML is due to non-hypoxic activation of $\operatorname{HIF}-1 \alpha[7,49]$. We depicted a new molecular scenario in which curcumin, by up-regulating miR-22 expression level, elicits the decrease of IPO7 and consequently hinders the nuclear translocation of HIF-1 $\alpha$ essential for its activity, thus affecting the metabolic enzyme profile of CML cells (Fig. 8).

Our study, for the first time, suggests the miR-22/IPO7/ HIF- $1 \alpha$ axis as new molecular target of curcumin, revealing innovative therapeutic implications of this natural compound for treatment of CML as well as of other cancer types in which HIF-1 $\alpha$ has a prominent role.

\section{Additional files}

Additional file 1: Figure S1. Cell growth was measured by MTT assay after $24 \mathrm{~h}$ of treatment with increasing doses of curcumin. Each point represents the mean \pm SD of three independent experiments. ${ }^{*} \leq 0.05$. (PPTX $42 \mathrm{~kb}$ )

Additional file 2: Table S1. MS Data of Protein ID. (XLSX 2197 kb) Additional file 3: Table S2. SWATH-MS Data. (XLSX $884 \mathrm{~kb}$ )

Additional file 4: Figure S2. Pearson's R2 showing the correlation between biological and technical replicates of Ctrl-K562 cells. (PPTX 178 kb)

Additional file 5: Figure S3. Pearson's R2 showing the correlation between biological and technical replicates of Curcu-K562 cells. (PPTX $185 \mathrm{~kb}$ )

Additional file 6: Table S3. DownReg Proteins_FunRichGOterms. (XLSX $50 \mathrm{~kb}$ )

Additional file 7: Table S4. UpReg Proteins_FunRichGOterms. (XLSX $35 \mathrm{~kb}$ )

Additional file 8: Table S5. Regulated Proteins_ClueGO Results. (XLSX $22 \mathrm{~kb}$ )

Additional file 9: Figure S4. Effects of Curcumin on HIF-1a activity, IPO7 expression and miR22 expression in LAMA84 cells. a Assay of the transcriptional activity of HIF-1a showing that in LAMA84 cells curcumin induced a reduction of HIF-1a activity compared to control cells. The reported values are the mean of three independent experiments. b qPCR (left panel) and representative Western blot (right panel) show that in LAMA84 cells curcumin treatment did not affect HIF-1a at both mRNA and protein level. The values (FOl: Fold of Induction) in the histogram are normalized against GAPDH and are the mean \pm SD of three independent experiments. C qPCR demonstrates that in LAMA84 cells curcumin induced a decrease of mRNA IPO7 expression. The values (FOl: Fold of Induction) in the histogram are normalized to GAPDH and are the mean \pm SD of three independent experiments. $d$ Representative western blot and corresponding densitogram showing that in LAMA84 cells curcumin inhibited the protein expression of IPO7. e qRT-PCR showing the ability of curcumin to induce in LAMA84 cells a significant increase of miR-22 expression. The values (FOl: Fold of Induction) in the histogram are normalized against RNU6-2 and are the mean \pm SD of two independent experiments. In the Western blot assay, actin was used as loading 
control. Intensities of proteins bands were calculated from the peak area of densitogram by using Image I software. Ctrl: control cells. Statistical significance was calculated vs Ctrl: ${ }^{*} p<0.05,{ }^{* *} p<0.01$. (PPTX $732 \mathrm{~kb}$ )

Additional file 10: Figure S5. Representative western blots and corresponding densitograms showing that in K562 (a) and LAMA84 cells (b) curcumin decreased nuclear levels of HIF-1a. Ponceau S of nuclear extract was used as loading control. Intensities of proteins band (in Ponceau $\mathrm{S}$ the band used is indicated with arrow) were calculated from the peak area of densitogram by using Image J software. Ctrl: control cells. (PPTX $809 \mathrm{~kb}$ )

Additional file 11: Figure S6. IPO7/miRNAs correlation. a Analysis performed by using microRNA target prediction software miRSearch V3.0 showed that IPO7 is a validated target of miR-22 and miR-9. b Analysis of predicted multiple targets performed by MicroRNA Target prediction (miRTar) tool (http://mirtar.mbc.nctu.edu.tw/human/) revealed within the CurcuDown-Regulated dataset the presence of several of miR-22 targets beside IPO7. No target of miR-9 was found. (PPTX $179 \mathrm{~kb}$ )

Additional File 12: Figure S7. Anti-proliferative effects of curcumin, imatinib and curcumin+imatinib combination on CML cell viability. Curcumin and imatinib were tested for their anti-proliferative effects on K562 (a) and LAMA84 cells (b). The assays were performed by using curcumin and imatinib singly (using the reported doses) or in combination (20 $\mathrm{\mu M}$ curcumin held constant and imatinib at reported concentrations. In K562 cells combination compound treatments showed significant differences compared to single imatinib treatments for all doses tested ( $p<0.001)$. In LAMA84 cells combination compound treatments showed significant differences compared to single imatinib treatments for lower doses tested ( $p<0.001$ at 0.1 and $0.2 \mu \mathrm{M}$ ), while no significant differences were observed between combination compound and imatinib at $0.5-5 \mu \mathrm{M}$ because high cell death occurred. Combination Index (Cl) analysis of growth inhibition in K562 (c) and LAMA84 cells (d) after $48 \mathrm{~h}$ incubation using curcumin $(20 \mu \mathrm{M})$ and imatinib (different concentrations). Data from Fig. S6a and S6b were converted to Fraction Affected (FrAf) and plotted against Combination Index (Cl). Results were as follows for imatinib concentration: $\boldsymbol{\Delta}=0.1 \mu \mathrm{M} ;=0.2 \mu \mathrm{M} ; \bullet=0.5 \mu \mathrm{M} ; \square=1 \mu \mathrm{M} ; 0=5 \mu \mathrm{M}$. Straight line on the graph designates a $\mathrm{Cl}$ equal to 1. Combination Index interpretation was as follows: $\mathrm{Cl}$ value of 1 indicates additivity; $\mathrm{Cl}<1$ indicates synergism; and $\mathrm{Cl}>1$ indicates antagonism. (PPTX $50 \mathrm{~kb}$ )

\section{Funding}

This work was supported by a grant from the Associazione Italiana per la Ricerca sul Cancro (AIRC) to R.A; FFR from the University of Palermo to R.A and S.F. This study was also developed with the contribution of National Operational Programme for Research and Competitiveness 2007-2013PON01_01059 "Sviluppo di una piattaforma tecnologica per il trattamento non invasivo di patologie oncologiche e infettive basate sull'uso di ultrasuoni focalizzati (FUS)".

\section{Availability of data and materials}

All data generated or analysed during this study are included in this published article and its Additional files except the MS proteomic data that have been deposited to the ProteomeXchange with identifier <PXD007771>

\section{Authors' contributions}

RA and SF conceived and supervised the project; SF, ST, FM and RA contributed to designed and/or interpreted experiments; FM and SF performed the proteomic analysis; ST conducted the experiments of cell and molecular biology; SF, ST and FM wrote the manuscript. All authors read and approved the final manuscript.

\section{Ethics approval and consent to participate}

Not applicable.

\section{Consent for publication}

Not applicable.

\section{Competing interests}

The authors declare that they have no competing interests.

\section{Publisher's Note}

Springer Nature remains neutral with regard to jurisdictional claims in published maps and institutional affiliations.

\section{Author details}

${ }^{1}$ Department of Biopathology and Medical Biotechnologies - Section of Biology and Genetics, University of Palermo, Palermo, Italy. ${ }^{2}$ Institute of Biomedicine and Molecular Immunology (IBIM), National Research Council, Palermo, Italy.

Received: 29 January 2018 Accepted: 13 July 2018

Published online: 25 July 2018

\section{References}

1. Deininger MW, Goldman JM, Melo JV. The molecular biology of chronic myeloid leukemia. Blood. 2000;96:3343-56.

2. Hughes TP, Hochhaus A, Branford S, Muller MC, Kaeda JS, Foroni L, Druker BJ, Guilhot F, Larson RA, O'Brien SG, et al. Long-term prognostic significance of early molecular response to imatinib in newly diagnosed chronic myeloid leukemia: an analysis from the international randomized study of interferon and STI571 (IRIS). Blood. 2010;116:3758-65.

3. Rousselot $P$, Huguet F, Rea D, Legros L, Cayuela JM, Maarek O, Blanchet O, Marit G, Gluckman E, Reiffers J, et al. Imatinib mesylate discontinuation in patients with chronic myelogenous leukemia in complete molecular remission for more than 2 years. Blood. 2007;109:58-60.

4. Ng KP, Manjeri A, Lee KL, Huang W, Tan SY, Chuah CT, Poellinger L, Ong ST. Physiologic hypoxia promotes maintenance of CML stem cells despite effective BCR-ABL1 inhibition. Blood. 2014;123:3316-26.

5. Chen H, Shen Y, Gong F, Jiang Y, Zhang R. HIF-alpha promotes chronic myelogenous leukemia cell proliferation by upregulating p21 expression. Cell Biochem Biophys. 2015;72:179-83.

6. Zhang H, Li H, Xi HS, Li S. HIF1alpha is required for survival maintenance of chronic myeloid leukemia stem cells. Blood. 2012;119:2595-607.

7. Zhao F, Mancuso A, Bui TV, Tong X, Gruber JJ, Swider CR, Sanchez PV, Lum $\mathrm{J}$, Sayed N, Melo JV, et al. Imatinib resistance associated with BCR-ABL upregulation is dependent on HIF-1alpha-induced metabolic reprograming. Oncogene. 2010;29:2962-72.

8. Braicu C, Mehterov N, Vladimirov B, Sarafian V, Nabavi SM, Atanasov AG, Berindan-Neagoe I. Nutrigenomics in cancer: revisiting the effects of natural compounds. Semin Cancer Biol. 2017;46:84-106.

9. Vallianou NG, Evangelopoulos A, Schizas N, Kazazis C. Potential anticancer properties and mechanisms of action of curcumin. Anticancer Res. 2015;35:645-51.

10. Taverna S, Fontana S, Monteleone F, Pucci M, Saieva L, De Caro V, Cardinale VG, Giallombardo M, Vicario E, Rolfo C, et al. Curcumin modulates chronic myelogenous leukemia exosomes composition and affects angiogenic phenotype via exosomal miR-21. Oncotarget. 2016;7:30420-39.

11. Taverna S, Giallombardo M, Pucci M, Flugy A, Manno M, Raccosta S, Rolfo C, De Leo G, Alessandro R. Curcumin inhibits in vitro and in vivo chronic myelogenous leukemia cells growth: a possible role for exosomal disposal of miR-21. Oncotarget. 2015;6:21918-33.

12. Gillet LC, Navarro P, Tate S, Rost H, Selevsek N, Reiter L, Bonner R, Aebersold R. Targeted data extraction of the MS/MS spectra generated by dataindependent acquisition: a new concept for consistent and accurate proteome analysis. Mol Cell Proteomics. 2012;0111(016717):11.

13. Li H, Wang Y, Fu Q, Li X, Wu C, Shen Z, Zhang Q, Qin P, Shen J, Xia X. Integrated genomic and proteomic analyses of high-level chloramphenicol resistance in campylobacter jejuni. Sci Rep. 2017;7:16973.

14. Deutsch EW, Csordas A, Sun Z, Jarnuczak A, Perez-Riverol Y, Ternent T, Campbell DS, Bernal-Llinares M, Okuda S, Kawano S, et al. The ProteomeXchange consortium in 2017: supporting the cultural change in proteomics public data deposition. Nucleic Acids Res. 2017;45:D1100-6.

15. Vizcaino JA, Csordas A, del-Toro N, Dianes JA, Griss J, Lavidas I, Mayer G, Perez-Riverol Y, Reisinger F, Ternent T, et al. 2016 update of the PRIDE database and its related tools. Nucleic Acids Res. 2016;44:D447-56.

16. Gao Y, Wang X, Sang Z, Li Z, Liu F, Mao J, Yan D, Zhao Y, Wang H, Li P, et al. Quantitative proteomics by SWATH-MS reveals sophisticated metabolic reprogramming in hepatocellular carcinoma tissues. Sci Rep. 2017;7:45913.

17. Pathan M, Keerthikumar S, Ang CS, Gangoda L, Quek CY, Williamson NA Mouradov D, Sieber OM, Simpson RJ, Salim A, et al. FunRich: an open 
access standalone functional enrichment and interaction network analysis tool. Proteomics. 2015;15:2597-601.

18. Bindea G, Mlecnik B, Hackl H, Charoentong P, Tosolini M, Kirilovsky A, Fridman WH, Pages F, Trajanoski Z, Galon J. ClueGO: a Cytoscape plug-in to decipher functionally grouped gene ontology and pathway annotation networks. Bioinformatics. 2009;25:1091-3.

19. Shannon P, Markiel A, Ozier O, Baliga NS, Wang JT, Ramage D, Amin N, Schwikowski B, Ideker T. Cytoscape: a software environment for integrated models of biomolecular interaction networks. Genome Res. 2003;13:2498-504.

20. Raimondo S, Naselli F, Fontana S, Monteleone F, Lo Dico A, Saieva L, Zito G, Flugy A, Manno M, Di Bella MA, et al. Citrus Limon-derived nanovesicles inhibit cancer cell proliferation and suppress CML xenograft growth by inducing TRAIL-mediated cell death. Oncotarget. 2015;6:19514-27.

21. Corrado C, Raimondo S, Flugy AM, Fontana S, Santoro A, Stassi G, Marfia A, lovino F, Arlinghaus R, Kohn EC, et al. Carboxyamidotriazole inhibits cell growth of imatinib-resistant chronic myeloid leukaemia cells including T315I Bcr-Abl mutant by a redox-mediated mechanism. Cancer Lett. 2011;300:205-14.

22. Chou TC. Drug combination studies and their synergy quantification using the Chou-Talalay method. Cancer Res. 2010;70:440-6.

23. Chou TC, Talalay P. Quantitative analysis of dose-effect relationships: the combined effects of multiple drugs or enzyme inhibitors. Adv Enzym Regul. 1984;22:27-55

24. Stelma T, Chi A, van der Watt PJ, Verrico A, Lavia P, Leaner VD. Targeting nuclear transporters in cancer: diagnostic, prognostic and therapeutic potential. IUBMB Life. 2016;68:268-80.

25. Chachami G, Paraskeva E, Mingot JM, Braliou GG, Gorlich D, Simos G. Transport of hypoxia-inducible factor HIF-1alpha into the nucleus involves importins 4 and 7. Biochem Biophys Res Commun. 2009;390:235-40.

26. Zhou S, Zhang S, Shen H, Chen W, Xu H, Chen X, Sun D, Zhong S, Zhao J, Tang J: Curcumin inhibits cancer progression through regulating expression of microRNAs. Tumour Biol 2017, 39:1010428317691680.

27. Lewis BP, Burge CB, Bartel DP. Conserved seed pairing, often flanked by adenosines, indicates that thousands of human genes are microRNA targets. Cell. 2005;120:15-20.

28. Grimson A, Farh KK, Johnston WK, Garrett-Engele P, Lim LP, Bartel DP. MicroRNA targeting specificity in mammals: determinants beyond seed pairing. Mol Cell. 2007;27:91-105.

29. Szczyrba J, Nolte E, Hart M, Doll C, Wach S, Taubert H, Keck B, Kremmer E, Stohr R, Hartmann A, et al. Identification of ZNF217, hnRNP-K, VEGF-A and IPO7 as targets for microRNAs that are downregulated in prostate carcinoma. Int J Cancer. 2013;132:775-84.

30. Sibbesen NA, Kopp KL, Litvinov IV, Jonson L, Willerslev-Olsen A, Fredholm S, Petersen DL, Nastasi C, Krejsgaard T, Lindahl LM, et al. Jak3, STAT3, and STAT5 inhibit expression of miR-22, a novel tumor suppressor microRNA, in cutaneous T-cell lymphoma. Oncotarget. 2015;6:20555-69.

31. Sreenivasan S, Thirumalai K, Danda R, Krishnakumar S. Effect of curcumin on miRNA expression in human Y79 retinoblastoma cells. Curr Eye Res. 2012:37:421-8.

32. Teiten $\mathbf{M H}$, Dicato $\mathbf{M}$, Diederich $M$. Curcumin as a regulator of epigenetic events. Mol Nutr Food Res. 2013:57:1619-29.

33. Sun M, Estrov Z, Ji Y, Coombes KR, Harris DH, Kurzrock R. Curcumin (diferuloylmethane) alters the expression profiles of microRNAs in human pancreatic cancer cells. Mol Cancer Ther. 2008;7:464-73.

34. Mirzaei H, Masoudifar A, Sahebkar A, Zare N, Nahand JS, Rashidi B, Mehrabian E, Mohammadi M, Mirzaei HR, Jaafari MR. MicroRNA: a novel target of curcumin in Cancer therapy. J Cell Physiol. 2017;2233:3004-15.

35. Wang X, Hang Y, Liu J, Hou Y, Wang N, Wang M. Anticancer effect of curcumin inhibits cell growth through miR-21/PTEN/Akt pathway in breast cancer cell. Oncol Lett. 2017;13:4825-31.

36. Kurien BT, Harris VM, Quadri SM, Coutinho-de Souza P, Cavett J, Moyer A, Ittiq B, Metcalf A, Ramji HF, Truong D, et al. Significantly reduced lymphadenopathy, salivary gland infiltrates and proteinuria in MRL-Ipr/lpr mice treated with ultrasoluble curcumin/turmeric: increased survival with curcumin treatment. Lupus Sci Med. 2015;2:e000114

37. Hani $U$, Shivakumar HG. Solubility enhancement and delivery systems of curcumin a herbal medicine: a review. Curr Drug Deliv. 2014;11:792-804

38. Liu W, Zhai Y, Heng X, Che FY, Chen W, Sun D, Zhai G. Oral bioavailability of curcumin: problems and advancements. J Drug Target. 2016;24:694-702.
39. Kurien BT, Singh A, Matsumoto $\mathrm{H}$, Scofield $\mathrm{RH}$. Improving the solubility and pharmacological efficacy of curcumin by heat treatment. Assay Drug Dev Technol. 2007;5:567-76.

40. Guo Y, Li Y, Shan Q, He G, Lin J, Gong Y. Curcumin potentiates the antileukemia effects of imatinib by downregulation of the AKT/mTOR pathway and $B C R / A B L$ gene expression in Ph+ acute lymphoblastic leukemia. Int J Biochem Cell Biol. 2015;65:1-11.

41. Fontana S, Alessandro R, Barranca M, Giordano M, Corrado C, Zanella-Cleon I, Becchi M, Kohn EC, De Leo G. Comparative proteome profiling and functional analysis of chronic myelogenous leukemia cell lines. J Proteome Res. 2007:6:4330-42.

42. Milacic V, Banerjee S, Landis-Piwowar KR, Sarkar FH, Majumdar AP, Dou QP. Curcumin inhibits the proteasome activity in human colon cancer cells in vitro and in vivo. Cancer Res. 2008;68:7283-92.

43. Shen M, Chan TH, Dou QP. Targeting tumor ubiquitin-proteasome pathway with polyphenols for chemosensitization. Anti Cancer Agents Med Chem. 2012;12:891-901.

44. Gatenby RA, Gillies RJ. Why do cancers have high aerobic glycolysis? Nat Rev Cancer. 2004;4:891-9.

45. Ganapathy-Kanniappan S. Taming tumor glycolysis and potential implications for immunotherapy. Front Oncol. 2017;7:36.

46. Ward PS, Thompson CB. Metabolic reprogramming: a cancer hallmark even Warburg did not anticipate. Cancer Cell. 2012;21:297-308.

47. Denko NC. Hypoxia, HIF1 and glucose metabolism in the solid tumour. Nat Rev Cancer. 2008;8:705-13.

48. Robey IF, Stephen RM, Brown KS, Baggett BK, Gatenby RA, Gillies RJ. Regulation of the Warburg effect in early-passage breast cancer cells. Neoplasia. 2008;10:745-56.

49. Klawitter J, Kominsky DJ, Brown JL, Christians U, Leibfritz D, Melo JV, Eckhardt SG, Serkova NJ. Metabolic characteristics of imatinib resistance in chronic myeloid leukaemia cells. Br J Pharmacol. 2009;158:588-600.

50. Choi H, Chun YS, Kim SW, Kim MS, Park JW. Curcumin inhibits hypoxiainducible factor-1 by degrading aryl hydrocarbon receptor nuclear translocator: a mechanism of tumor growth inhibition. Mol Pharmacol. 2006:70:1664-71.

51. Shan B, Schaaf C, Schmidt A, Lucia K, Buchfelder M, Losa M, Kuhlen D, Kreutzer J, Perone MJ, Arzt E, et al. Curcumin suppresses HIF1A synthesis and VEGFA release in pituitary adenomas. J Endocrinol. 2012;214:389-98,

52. Niu M, Wu S, Mao L, Yang Y. CRM1 is a cellular target of curcumin: new insights for the myriad of biological effects of an ancient spice. Traffic. 2013; 14:1042-52.

53. Turner JG, Dawson J, Cubitt CL, Baz R, Sullivan DM. Inhibition of CRM1dependent nuclear export sensitizes malignant cells to cytotoxic and targeted agents. Semin Cancer Biol. 2014;27:62-73.

54. Turner JG, Dawson J, Emmons MF, Cubitt CL, Kauffman M, Shacham S, Hazlehurst LA, Sullivan DM. CRM1 inhibition sensitizes drug resistant human myeloma cells to topoisomerase II and proteasome inhibitors both in vitro and ex vivo. J Cancer. 2013:4:614-25

55. Kazim S, Malafa MP, Coppola D, Husain K, Zibadi S, Kashyap T, Crochiere M, Landesman Y, Rashal T, Sullivan DM, Mahipal A. Selective nuclear export inhibitor KPT-330 enhances the antitumor activity of gemcitabine in human pancreatic Cancer. Mol Cancer Ther. 2015;14:1570-81.

56. Goel A, Aggarwal BB. Curcumin, the golden spice from Indian saffron, is a chemosensitizer and radiosensitizer for tumors and chemoprotector and radioprotector for normal organs. Nutr Cancer. 2010;62:919-30.

57. Limtrakul P. Curcumin as chemosensitizer. Adv Exp Med Biol. 2007;595: 269-300.

58. Lankheet NAG, Desar IME, Mulder SF, Burger DM, Kweekel DM, van Herpen CML, van der Graaf WTA, van Erp NP. Optimizing the dose in cancer patients treated with imatinib, sunitinib and pazopanib. Br J Clin Pharmacol. 2017:83:2195-204. 